\title{
Calibrating Partial Factors - Methodology, Input Data and Case Study of Steel Structures
}

\author{
Vitali Nadolski1, Árpád Rózsás², Miroslav Sýkora ${ }^{3 *}$ \\ 1 Department of Metal and Timber Structures, Faculty of Civil Engineering, \\ Belarusian National Technical University \\ Independence Ave. 65, 220013, Minsk, Republic of Belarus \\ 2 TNO Building and Construction Research \\ PO Box 155, 2600 AD Delft, The Netherlands \\ ${ }^{3}$ Klokner Institute, \\ Czech Technical University in Prague, \\ Solinova 7, 16608 Prague, Czech Republic \\ * Corresponding author, e-mail: miroslav.sykora@cvut.cz
}

Received: 09 July 2018, Accepted: 13 December 2018, Published online: 29 January 2019

\begin{abstract}
Partial factors are commonly based on expert judgements and on calibration to previous design formats. This inevitably results in unbalanced structural reliability for different types of construction materials, loads and limit states. Probabilistic calibration makes it possible to account for plentiful requirements on structural performance, environmental conditions, production and execution quality etc. In the light of ongoing revisions of Eurocodes and the development of National Annexes, the study overviews the methodology of probabilistic calibration, provides input data for models of basic variables and illustrates the application by a case study. It appears that the partial factors recommended in the current standards provide for a lower reliability level than that indicated in EN 1990. Different values should be considered for the partial factors for imposed, wind and snow loads, appreciating the distinct nature of uncertainties in their load effects.
\end{abstract}

Keywords

Eurocodes, optimization, partial factor, probabilistic calibration, target reliability

\section{Introduction}

At present, the design of buildings and bridges is prevalently based on verification of limit states. In accordance with EN 1990 [1], the limit state is a "state beyond which the structure no longer fulfils the relevant design criteria". Structural design is intended to ensure that a limit state is exceeded with a probability lower than a given target failure probability. For verification of limit states, EN 1990 [1] allows the application of probabilistic methods and semi-probabilistic methods including the partial factor method.

Using probabilistic methods, a limit state is verified by direct comparison of the calculated (notional) failure probability with a specified target value given for a reference period adopted for reliability analysis. The flexibility of probabilistic methods makes it possible to reflect structure-specific conditions including requirements on structural performance and local environmental effects. Use of these advanced methods is often justified in cases when very little or very detailed information about structures is available (material properties, geometry, loads) or when expected failure consequences are significant (economic or ecological losses, fatalities and injuries). These methods are often applied when assessing existing structures $[2,3]$. Target reliability levels may need to be updated in the case of exceptional failure consequences, or in the case of the large cost of safety measures. In these cases, economic optimization provides sufficiently reliable structures with minimized life-cycle costs $[4,5,6]$.

However, use of probabilistic methods in design practice is often hindered by the complexity of their implementation and the requirements of knowledge and the experience of a designer. Therefore, the partial factor method in which the variability of basic variables and model uncertainty is considered by characteristic values and a system 
of partial factors is prevalently used in engineering practice at the present time. According to EN 1990 [1], 6.1(1)P, the basic requirement of the partial factor method is as follows: "It shall be verified that, in all relevant design situations, no limit state is exceeded when design values for actions or effects of actions and resistances are used in the design models".

Partial factors in the past standards of many countries were often based on expert judgements and on calibration to previous design methods, such as allowable (or permissible) stresses or safety factors. Furthermore, the reliability level was often not explicitly stated and it is unknown whether a comprehensive, unified probabilistic rationale governed the codification process. This inevitably resulted in unbalanced structural reliability, in the case of wind and snow loads often lower than the target levels provided in EN 1990 $[1,51,52,65]$. In past standards, some partial factors (e.g. for snow loads) were dependent on the ratio of variable to permanent actions, which seems to be an improvement to the fixed partial factors in Eurocodes [50, 53].

In general, partial factors can be established by:

a. Expert judgement;

b. Non-probabilistic calibration with respect to design procedures proven by many years of experience and deemed to provide current best practice, e.g. adjusting partial factors in order to reach design levels similar to those based on the allowable stresses method;

c. Statistical method based on the given probability of exceeding the design value, i.e. the design value being a prescribed fractile;

d. Probabilistic reliability methods taking into account related aleatory and epistemic uncertainties, significance of basic variables with respect to a considered limit state and required target level;

e. Probabilistic cost minimization in order to achieve optimum design strategies for specified failure modes, considering structural costs and expected failure consequences.

The main objectives when selecting and calibrating partial factors are to achieve a uniform reliability with respect to different types of construction materials, types of loads and different limit states such as STR - design of structural components, EQU - static equilibrium or GEO geotechnical design according to EN 1990 [1]. Commonly, the calibrations are typically focused on a generic structure or its key structural member(s), or groups of structures, considering a range of typical variable loads such as climatic actions, imposed and traffic loads.
Probabilistic calibration is the most advanced procedure, making it possible to take into consideration a wide range of requirements regarding structural performance, environmental conditions, production, execution quality, etc. Recommendations of the present standards accepted in the European Union, USA, Canada and other countries are commonly based on a mixture of approaches b) and c) $[8,9$, $10,11,12]$, leading in some cases to overly conservative or unsafe design solutions $[12,13,14]$.

The main objective of probabilistic partial factor calibration is to provide for a required reliability level. The calibrated partial factors shall ensure that the reliability levels of typical structures are as close as reasonably possible to the specified target levels, regardless of construction materials, actions on structures and environmental conditions, whilst providing a simple design format.

The partial factor system allows for reliability differentiation considering national conditions, including economic factors and environmental effects. In the light of the present revisions of Eurocodes and the ongoing process of development of National Annexes where partial factors and target reliability levels can be specified, the present study is intended to:

- Overview methodology for calibrations (Section 2).

- Provide input data (Section 3 and Annex A).

- Illustrate the procedure by an extensive case study (Sections 4 and 5).

In the case study, reliability levels associated with the presently accepted partial factors for structural design are verified (Section 4), and partial factors are calibrated considering a specified target reliability level, typical structural members, common limit states and a wide range of load combinations (Section 5). The case study is related to the design practice, the execution of steel structures and to the climatic conditions deemed to be representative for most Central European countries. As structural reliability depends strongly on the assumptions about probabilistic models of basic variables, it is important to use a kind of standardized probabilistic models in order to allow comparisons of results obtained by various reliability studies. ISO 2394 [7] emphasizes that "Specified failure probabilities should always be considered in relation to the adopted calculation and probabilistic models." This is why the results of detailed literature survey focused on probabilistic models for basic variables relevant for Central European countries are reported in Annex A.

The calibration procedure is consistent with the recently revised ISO 2394 [7], which provides the basis for developing structural design codes. 


\section{Problem formulation}

\subsection{Limit state function}

Reliability analysis and calibration of partial factors is based on the limit state function, the negative values of which are considered to indicate structural failure. For reliability analysis of the ultimate limit states of steel load-bearing members, the generic function $g(\boldsymbol{X})$ is taken into account:

$g(\boldsymbol{X})=R-E=K_{R} R-K_{E}\left(G+C_{0} Q\right)$,

where the basic variables $\boldsymbol{X}$ are denoted as follows: $K_{R}=$ uncertainty in the resistance model; $R=$ resistance of a cross section or members - for example resistance of cross section for bending member $R=W f_{y}$ with $W=$ section modulus and $f_{y}=$ yield strength of steel; $K_{E}=$ uncertainty in a load effect $E$ with possible distinction between bending, shear and compression; $G=$ permanent load including load model uncertainties; $C_{0}=$ time-invariant component of variable action such as shape, exposure and thermal factors, and load model uncertainty; $Q=$ time-variant component of variable action, related to maximum value for a given reference period.

When the probabilistic models of basic variables are known, failure probability $P[g(\boldsymbol{X})<0]$ can be determined by the reliability theory methods [15]. In reliability assessment, obtained failure probability is then compared with a target level.

\subsection{Target reliability}

As a measure of safety, the reliability index $\beta$ is associated with failure probability through the inverse of the standardized normal cumulative distribution, EN 1990 [1] and ISO 2394 [7]. The target levels are often differentiated in view of various aspects such as the cost of safety measures, failure consequences, reference period or a design working life [16].

Target reliabilities are often based on:

a. Comparisons with current satisfactory design practice [72];

b. Human safety criteria $[7,59]$;

c. Economic optimization focused on life-cycle costs of representative structures - for instance buildings $[4,5]$, bridges $[73,74]$, or tunnels $[75]$ or a series of structures under systematic replacements over a long period $[76,81]$.

EN 1990 [1] recommends the target reliability index $\beta$ for the two reference periods - 1 and 50 years; see example for medium consequences of failure in Table 1.
Table 1 Target reliability indices for different reference periods and comparable failure consequences according to selected standards

\begin{tabular}{lccc}
\hline Standard & $\begin{array}{c}\text { Failure } \\
\text { consequences }\end{array}$ & Reference period & $\beta$ \\
\hline EN 1990 [1] & medium & 50 years (1 year) & $3.8(4.7)$ \\
ISO 2394:1998 & moderate & life-time & $3.1^{*}$ \\
ISO 2394 [7] & moderate & 1 year & $4.2^{* *}$ \\
\hline
\end{tabular}

*For moderate relative cost of safety measures. ${ }^{* *}$ For normal relative cost of safety measures.

The couple of $\beta$-values given in Table 1 in EN 1990 [1] is provided for two reference periods used for reliability verification. These values should correspond approximately to the same reliability level (same structural resistance):

- $\beta=3.8$ should thus be used provided that probabilistic models of basic variables are related to the reference period of 50 years.

- Approximately the same reliability level is reached when $\beta=4.7$ is applied using statistical models and parameters related to one year, and when failure probabilities in individual years are independent.

When compared to EN 1990 [1], a more detailed and substantially different recommendation was provided by ISO 2394:1998. The target reliability index was given for a working life and related not only to the consequences but also to the relative costs of safety measures (Table 1). Note that the consideration of the costs of safety measures is particularly important for existing structures.

Similar recommendations are provided in the Probabilistic Model Code of the Joint Committee on Structural Safety JCSS [17] and in the recent revision of ISO 2394 [7] using economic optimization. Recommended target reliability indices are again related to both the consequences and relative costs of safety measures, but for the reference period of one year (Table 1). In addition, ISO 2394:1998 and ISO 2394 [7] include acceptance criteria for human safety.

In ASCE 7-10 [66] buildings and other structures are classified into four risk categories according to the number of persons at risk. Category I is associated with few persons at risk and category IV with tens of thousands. For all loads addressed by the standard except earthquake, the standard aims to reach target annual reliability from 3.7 for category I up to 4.4 for category IV.

It is noted that the target reliability levels in the codes of practice provide criteria for limit states that do not account for human errors, i.e. the target levels should be compared with the so-called notional reliability indicators, ISO 2394 [7]. Target reliability levels are essential for deriving partial factors $[67,68]$. 


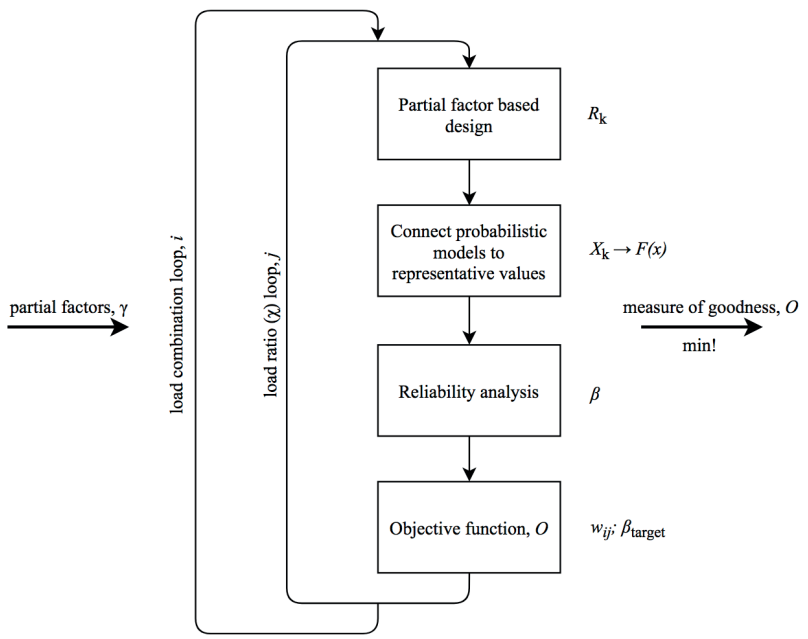

Fig. 1 Algorithm of calibration

\subsection{Basis of calibration}

\subsubsection{Algorithm}

The scope of calibration should cover construction practices and climatic conditions of a particular country or region and selected limit state(s). The objective is to obtain partial factors that minimize a specific deviation from a given target reliability and to combine and enhance the results using expert judgements that may, for instance, reflect consistency with the provisions of previous standards. An overview of the main steps of the calibration procedure is presented in Fig. 1 (see Section 5.1 for further details).

Three different load combinations with distinct leading variable actions and nine characteristic load ratios $(\chi$ - see Sub-section 2.3.2) are considered to cover a wide range of structures when applying the iterative procedure in Fig. 1. The optimization starts off with the partial factor-based design leading to the required characteristic resistance $\left(R_{\mathrm{k}}\right)$; see Sub-section 2.3.2. Probabilistic models are then based on representative values (Section 3 and Annex A), reliability is analyzed, and the objective function is evaluated. This procedure is repeated by changing the partial factors to iteratively minimize the objective function. Normally same target reliability is considered for all structures under investigation.

\subsubsection{Partial factor-based design}

The partial factor-based format provided by Eurocodes is considered along with load combinations involving a single variable action. The simplified ultimate limit state load combination rule - Eq. 6.10 in EN 1990 [1] - is applied:

$R_{\mathrm{k}} / \gamma_{\mathrm{M}} \geq \gamma_{G} G_{\mathrm{k}}+\gamma_{Q} C_{0} Q_{\mathrm{k}}$,
In some countries this rule is recommended for the design of steel structures. The values of the partial factors for resistance $\left(\gamma_{\mathrm{M}}\right)$, permanent $\left(\gamma_{G}\right)$ and variable $\left(\gamma_{Q}\right)$ actions are obtained as follows:

$\gamma_{\mathrm{M}}=\gamma_{R \mathrm{~d}} \gamma_{\mathrm{m}} ; \gamma_{G}=\gamma_{S \mathrm{~d}} \gamma_{g} ; \gamma_{Q}=\gamma_{S \mathrm{~d}} \gamma_{C 0} \gamma_{q}$

where:

$\gamma_{R \mathrm{~d}}=$ partial factor reflecting uncertainties in a resistance model and variability of geometrical characteristics;

$\gamma_{\mathrm{m}}=$ partial factor for a material property (yield strength of steel here);

$\gamma_{S \mathrm{~d}}=$ partial factor taking into account uncertainties in a load effect model and variability of geometrical characteristics;

$\gamma_{g}$ and $\gamma_{q}=$ partial factors for permanent load and time-variant component of a variable load, respectively; and

$\gamma_{C 0}=$ partial factor accounting for uncertainties in a load model and in time-invariant components of a variable action.

In addition to a constant partial factor for variables actions $\left(\gamma_{Q}\right)$, an alternative formulation with a linearly varying partial factor is also considered, consistent with the provisions of some past standards (see Section 1):

$\gamma_{Q}=a+b \chi$

where $a$ and $b$ are the intercept and slope parameters to be calibrated, and the load ratio $\chi$ is the ratio between characteristic variable to characteristic total load, $\chi=C_{0, \mathrm{k}} Q_{\mathrm{k}} /\left(G_{\mathrm{k}}+C_{0, \mathrm{k}} Q_{\mathrm{k}}\right)$.

This formulation is motivated by significant differences in distribution types and coefficients of variation of variable and permanent actions. The partial factor based on equation (4) might allow the achievement of a markedly better balanced reliability level than by using a fixed $\gamma_{Q}$ value. Note that for snow loads, a linearly varying partial factor was applied in the superseded Hungarian national standard MSZ; the partial factor was varied from 1.40 to 1.75 for different $\chi$-values [53]. Similarly, the partial factor for snow load for roof members is dependent on the ratio of $G_{\mathrm{k}} / S_{\mathrm{k}}$ in Belarus [50] as indicated in Section 4.

\subsubsection{Measure of closeness}

The following objective function is used as a measure of closeness to target reliability:

$O(\gamma)=\sum_{i} \sum_{j}^{\text {load comb.load ratio }} w_{i, j}\left(\beta_{\mathrm{t}}-\beta_{i, j}(\gamma)\right)^{2}$, 
where $w_{i, j}$ is a weight factor that accounts for the prevalence of a design condition. In this study it is identified by a leading variable action and by a load ratio $\chi$. The selected weights are summarized in Table 2, partly based on the study by Ellingwood et al. [55] and partly based on empirical experience from Belarusian construction practice. Since wind action typically has substantial horizontal effects, while the effects of permanent, snow and imposed loads are mostly vertical, the load ratios for wind-dominated structures are dependent on a structure type and the weights are hard to approximate. To reflect this uncertainty, two sets of weights $\left(W_{1}, W_{2}\right)$ are considered (Table 2). Unless stated otherwise, all the results presented in Section 5 correspond to the $W_{1}$ alternative.

The weights provided in Table 2 are in broad agreement with the generic information provided in [77] where no distinction amongst types of variable loads is made, however. It must be emphasized that the weights are construction material- and structural member-dependent - see Subsection 6.3.

In addition, an alternative asymmetric objective function recommended by Hansen and Sørensen [11] is tested to investigate the effect of a function type. In terms of reliability indices, the asymmetric formulation penalizes negative deviation from target reliability:

$$
O(\gamma)=\sum_{i}^{\text {load comb.load ratio }} \sum_{j} w_{i, j}\left(4.35\left(\beta_{\mathrm{t}}-\beta_{i, j}(\gamma)\right)+\exp \left[-4.35\left(\beta_{\mathrm{t}}-\beta_{i, j}(\gamma)\right)\right]-1\right)
$$

\section{Probabilistic models of basic variables recommended for calibration}

Probabilistic models of basic variables have a substantial effect on predicted reliability levels and consequently affect the values of partial factors related to a specified target reliability level. Therefore, systematic and detailed investigation of appropriate probabilistic models of basic variables and their parameters is needed to provide input data for reliability analyses and probabilistic calibrations.

In general, the distribution and values of its parameters should be selected on the basis of statistical analysis of available experimental data. In the construction industry, experimental data are often insufficient for predicting

Table 2 Load ratios and weights in \% proposed for calibration

\begin{tabular}{lccccccccc}
\hline$\chi$ & 0.1 & 0.2 & 0.3 & 0.4 & 0.5 & 0.6 & 0.7 & 0.8 & 0.9 \\
\hline Snow, $w_{S}$ & 5 & 10 & 10 & 10 & 10 & 15 & 20 & 15 & 5 \\
Imp., $w_{I}$ & 5 & 5 & 15 & 15 & 20 & 15 & 15 & 5 & 5 \\
Wind, $w_{W 1}$ & 5 & 10 & 10 & 10 & 10 & 15 & 20 & 15 & 5 \\
Wind, $w_{W 2}$ & 11 & 11 & 11 & 11 & 12 & 11 & 11 & 11 & 11 \\
\hline
\end{tabular}

extremely rare events such as failures in the Ultimate Limit States. Therefore, the use of probabilistic models is often justified by theoretical arguments (for instance by the extreme value theory or by the central limit theorem) or simply based on conventions; see basic information on climate load modelling in Annex A. Note that distinctly different approaches need to be applied in modelling traffic load extremes $[78,79]$. This is why JCSS is periodically revising the general recommendations for selecting probabilistic distributions and specifying input parameters [17].

Probabilistic models of basic variables adopted in various studies are often significantly different - see Subsection 6.1 for the comparison with other calibration studies. Different reliability levels are then inevitably obtained and diverse recommendations concerning the values of reliability elements - partial factors, combination factors and other parameters ensuring target reliability levels in structural design - are provided. In calibration studies, it is thus important to provide full information on probabilistic models of resistance and load effect variables on which recommended reliability elements are based. ISO 2394 [7] notes that the use of calibrated values jointly with different models for basic variables can cause unintended high or low reliability levels. That is why the recommendations of JCSS are followed in the present analysis; conditions specific to Central European countries are mostly reflected by the values of the parameters of probabilistic distributions such as mean and coefficient of variation.

Table 3 shows the probabilistic models of basic variables considered in the following reliability analysis and calibration study focused on steel structural members. For the parameters specified by intervals, the midpoints are used to calculate reliability indices in the partial factor calibration. The distributions considered in this study normal, lognormal, and Gumbel - are defined in structural reliability textbooks such as [15].

\section{Verification of present design formats}

To provide motivation for the following calibration study and indicate what reliability levels could be deemed to correspond to current best practice, the reliability of a structural member designed using partial factors given in Belarusian standards $[49,50]$ is analyzed. The basic principles of the Belarusian standards (commonly referred to as SNiP standards) and a comparison with the procedures accepted in Eurocodes were provided in [48] with a particular focus on the design of steel structures. The major 
Table 3 Summary of probabilistic models

\begin{tabular}{|c|c|c|c|c|}
\hline Basic variable & $X$ & Dist. & $\mu_{X} / X_{k}$ & $V_{X}$ \\
\hline General resistance & $R$ & LN & a), $X_{\mathrm{k}} \approx 2 \%$ fractile $=X_{0.02}$ & $0.05-0.08$ \\
\hline Resistance model uncertainty & $K_{R}$ & $\mathrm{LN}$ & $1.0-1.15$ & $0.05-0.10$ \\
\hline - Uniform bending moment (plastic resistance) & & & 1.0 & 0.05 \\
\hline $\begin{array}{l}\text { - Gradient bending moment (plastic resistance), bending resistance with the loss of } \\
\text { stability (general case), axial compression with the loss of stability }\end{array}$ & & & 1.15 & 0.1 \\
\hline - Yielding flexural resistance & & & 1.1 & 0.05 \\
\hline - Bending resistance with the loss of stability (rolled or equivalent welded profiles) & & & 1.1 & 0.08 \\
\hline Load effect, model uncertainty & $K_{E}$ & $\mathrm{LN}$ & 1 & 0.10 \\
\hline Permanent load & $G$ & $\mathrm{~N}$ & 1 & $0.07-0.10$ \\
\hline Snow load on ground (annual maxima) & $S_{1}$ & Gum & b), $X_{\mathrm{k}}=X_{0.98}$ & $0.48-0.62$ \\
\hline Snow load - time-invariant component & $C_{0, S}$ & $\mathrm{~N}$ & 1 & 0.15 \\
\hline Imposed load (5-year maxima) & $I_{5}$ & Gum & c), $X_{\mathrm{k}} \approx X_{0.995}$ & $0.9-1.3$ \\
\hline Imposed load - time-inv. comp. & $C_{0, I}$ & $\mathrm{~N}$ & 1 & 0.10 \\
\hline Basic wind velocity pressure (annual max.) & $W_{1}$ & Gum. & b), $X_{\mathrm{k}}=X_{0.98}$ & $0.30-0.50$ \\
\hline Wind load - time-inv. comp. & $C_{0, W}$ & $\mathrm{~N}$ & 0.8 & 0.30 \\
\hline
\end{tabular}

a) $\sqrt{ }\left\{1+V_{X}^{2} \exp \left[-\Phi^{-1}(0.02) \sqrt{ } \ln \left(1+V_{X}^{2}\right)\right]\right\}$ where $\Phi$ is the standard normal cumulative distribution function. Note that the overview provided in A.1.1 suggests $\mu_{R} / R_{k}=1.2$ and $V_{R}=0.085$ for resistance including the variability of geometrical characteristics, and thus the characteristic value $R_{k}$, corresponds to $1.8 \%$ fractile when a two-parameter lognormal distribution is considered.

b) $1 /\left\{1-V_{X} \sqrt{6} / \pi[\gamma+\ln (-\ln 0.98)]\right\}$ where $\gamma=0.577$ is the Euler-Mascheroni constant.

c) $\mu_{X} / X_{\mathrm{k}} \approx 0.2$ for typical office areas. The coefficient of variation decreases with an increasing floor area, as indicated by the range from 0.9 to 1.3; the upper bound corresponds to a loaded area of $30 \mathrm{~m}^{2}$ while the lower bound is obtained for a loaded area of $100 \mathrm{~m}^{2}$. A middle value of 1.1 corresponds approximately to $50 \mathrm{~m}^{2}$ and was used by Gulvanessian and Holicky [13] in their investigations of reliability levels associated with the load combination rules provided in EN 1990 [1].

Table 4 Comparison of characteristic values and partial factors according to Eurocodes and SNiP standards

\begin{tabular}{|c|c|c|c|}
\hline \multirow{2}{*}{ Parameters } & & \multicolumn{2}{|c|}{ Partial factors applied in this section } \\
\hline & & Eurocodes (Belarusian national recommendations) & $\mathrm{SNiP}$ \\
\hline Permanent load & $G_{\mathrm{k}}^{*} / G_{\mathrm{k}}=1$ & $\gamma_{G}=1.35 ; \xi=0.85$ & $\gamma_{G}^{*}=1.15$ \\
\hline Imposed load & $Q_{\mathrm{k}}^{*} / Q_{\mathrm{k}}=1$ & $\gamma_{Q}=1.5 ; \psi_{0, Q}=0.7$ & $\gamma_{Q}{ }^{*}=1.3$ or $1.2 ; \psi_{Q}^{*}=0.9$ \\
\hline Snow load & $S_{\mathrm{k}}^{*} / S_{\mathrm{k}}=0.83$ & $\gamma_{S}=1.5 ; \psi_{0 . \mathrm{s}}=0.6$ & $\gamma_{S}^{*}=1.5$ or $1.6 ; \psi_{S}^{*}=0.9$ \\
\hline Yield strength & $f_{\mathrm{y}}^{*} / f_{\mathrm{y}}=1$ & $\gamma_{\mathrm{M} 0}=1.025$ & $\gamma_{\mathrm{c}}=1 ; \gamma_{\mathrm{m}}=1.025$ \\
\hline Reliability differentiation & - & $k_{\mathrm{FI}}=0.9(\mathrm{RC} 1), k_{\mathrm{FI}}=1(\mathrm{RC} 2), k_{\mathrm{FI}}=1.1(\mathrm{RC} 3)$ & $\begin{array}{c}0.8 \leq \gamma_{\mathrm{n}}<0.95\left(\text { level III) }, \gamma_{\mathrm{n}}=\right. \\
0.95(\mathrm{II}), 0.95<\gamma_{\mathrm{n}} \leq 1.2(\mathrm{I})\end{array}$ \\
\hline
\end{tabular}
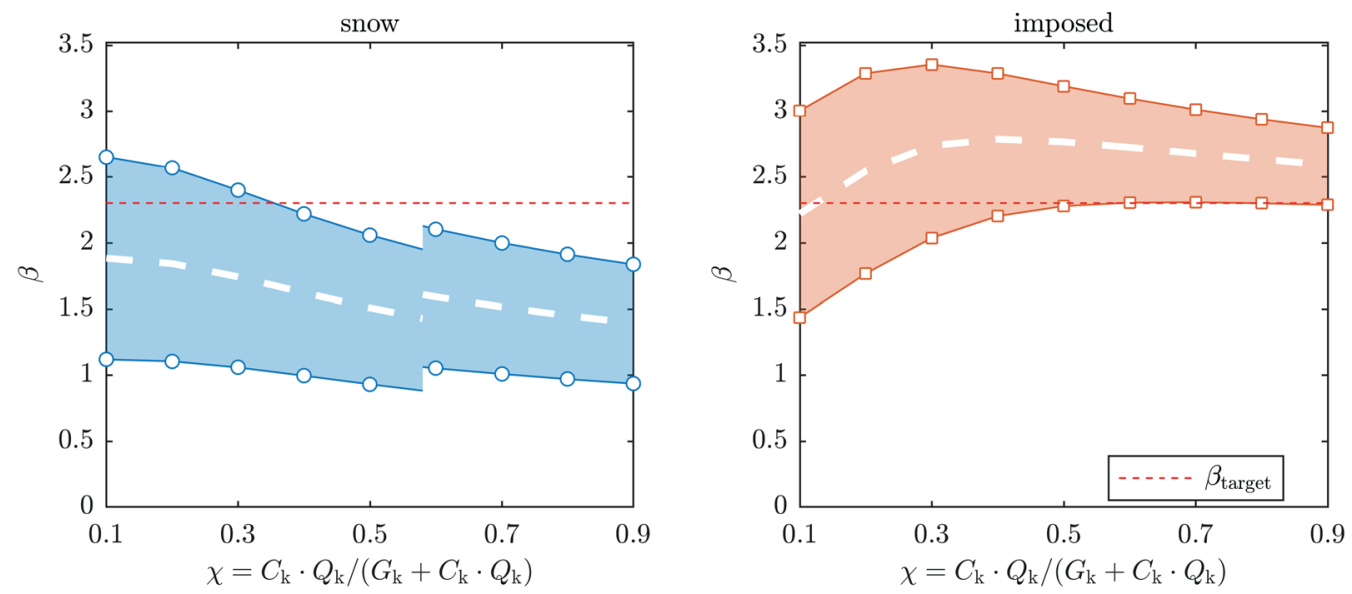

Fig. 2 Variation of reliability index intervals $\beta$ with load ratio $\chi$ for a reference period of 50 years for snow and imposed load 
differences include load combination rules, definition of characteristic values and different values of partial factors. Information on the two latter aspects is given in Table 4.

In Table 4 the values given in the SNiP standards are denoted by asterisk, *. Partial factor $\gamma_{Q}{ }^{*}$ for the imposed load depends on a total normative ( characteristic) value of the load: $\gamma_{Q}{ }^{*}=1.3$ for a normative value lower than $2.0 \mathrm{kN} / \mathrm{m}^{2}$ and $\gamma_{Q}{ }^{*}=1.2$ otherwise. Partial factor $\gamma_{S}{ }^{*}$ for snow load is 1.5 for structural members, excluding roof members for which $\gamma_{S}{ }^{*}$ is 1.5 for $G_{\mathrm{k}}{ }^{*} / S_{\mathrm{k}}^{*} \geq 0.8$ and 1.6 otherwise.

Variation of reliability index with the load ratio is shown in Fig. 2 in which a reference period of 50 years for imposed and snow loads is considered. A case with a leading wind action is not analyzed since the comparison of substantially different models in SNiP and Eurocodes is beyond the scope of this study.

Fig. 2a) indicates the upper and lower bounds on the reliability index for a structural member exposed to permanent and imposed loads $\left(\gamma_{Q}{ }^{*}=1.3\right)$. With reference to Table 3 , the lower bound corresponds to the most unfavorable combination of input parameters (low biases and large CoVs of resistance variables combined with large biases and low CoVs of load effect variables), while the upper bound is obtained for the most favorable combination of input parameters. The reliability levels for a structural member exposed to permanent and snow loads are shown in Fig. 2b). A reliability index of 2.3 may be seen as an average level reached when using the partial factors given above. This design procedure may be considered as providing sufficient reliability for steel structures (current best practice), as acceptable failure rates have been experienced and the construction industry does not require increasing reliability levels. Similar reliability indices were obtained for the partial factors provided in the standards of the Russian Federation [47], Belarus [48] and in previous Czech standards.

It might be argued that the reliability levels obtained for the current partial factors are unrealistically low and the reliability analysis fails to provide a true picture, as excessive failure rates are not observed. Low reliability estimates can be attributed to the following aspects:

- The probabilistic models for the time-invariant components of climatic actions are deemed to be associated with so-called hidden safety; in particular shape factors for wind and snow loads need to be further investigated. More favorable values were foreseen in $[56,57,58,90]$. For instance the recent study [60] indicates that the Eurocode global wind action often overestimates the wind action measured in wind tunnels. The overestimation is often more than $40 \%$. This is attributable to simplifications related to spatial and temporal correlation of wind pressures across the structure, topographical effects or the effect of wind directionality [64].

- Honfi [61] indicates that imposed load models are commonly based on tradition and expert judgements. The JCSS imposed models, which provide the basis for the model adopted in this study, seem to yield higher load magnitudes than other probabilistic models reported e.g. in $[62,63]$ and may be deemed to be conservative. In addition, most of the imposed load surveys were carried out more than 30 years ago and updates regarding the present use of buildings are needed.

- The introduction of better calculation models (possibly associated with reduced model uncertainties), additional requirements on structural robustness and quality control measures result in markedly improved structural performances [56].

However, a broad consensus on these issues has not yet been reached.

\section{Calibration of partial factors}

\subsection{Basic considerations}

A numerical application of the calibration procedure and proposed probabilistic modes is performed in the following steps (cf. Fig. 1):

1. Partial factor based design: For simplicity, a single limit state function according to equation (1) is taken into account. The partial factors given in Table $4-\gamma_{\mathrm{M} 0}=1.025, \gamma_{G}=1.35$, and 1.5 for variable actions - and the characteristic values of the basic variables are selected as initial values for calibration to achieve an "ideal" design solution, $R_{\mathrm{d}}=E_{\mathrm{d}}$, for a given value of the load ratio. Note that several failure modes (limit state functions), assigned possibly with different weights due to their practical relevance, can be readily employed in calibration.

2. Probabilistic models are established for the specified characteristic values according to Table 3 . Unless otherwise stated, mid-values from the recommended ranges for the statistical parameters are considered.

3. Based on the results in Section 4, $\beta_{\mathrm{t}}=2.3$ and a reference period equal to a common design working life of 50 years are initially considered for calibration, assuming an investigated structure can be classified in reliability class RC2 according to EN 1990 [1]. 
Then, $\beta_{\mathrm{t}}=3.8$ (Table 1) is taken into consideration to indicate the values of partial factors corresponding to the target levels given in EN 1990 [1].

4. Constrained numerical optimization is used to obtain the partial factors with minimum objective function value according to symmetric and asymmetric objective functions, equation (5) and equation (6), respectively. Constant lower and upper bounds on each optimized partial factor are taken into account - to be consistent with previous calibration studies and current codes of practice, all the partial factors are bounded in the range from 0.8 to 2.8. After testing several constrained optimization algorithms, a sequential quadratic programming ( $\mathrm{SQP}$ ) algorithm is selected as it proves to be the most robust for the problem under investigation. It is mainly attributed to its ability to recover from infinite and not-defined objective function values. The SQP algorithm with multiple starting points is applied [54]. The use of the latter is motivated by the occurrence of multiple minima with nearly the same objective function values. These values are deemed equally good and the selection of a recommended set of partial factors is governed by the closeness of values to the current partial factors - the closer, the better - so as to cause minimal disturbance.

The SQP algorithm is applied following [54, 82, 83]; both convergence criteria - optimality and step tolerance - are $10^{-4}$. In this study, the SQP algorithm is implemented in Matlab implementation through function fmincon along with algorithm sqp. Since different optimal partial factors yield the same value of the objective function value upon running the algorithm with different starting positions, each optimization task is completed with 100 different starting positions. These are randomly selected considering the lower and upper bounds on the partial factors. The 100 optimizations are executed in parallel batches on a multithreaded CPU.

5. Using the calibrated partial factors, hybrid probabilistic-interval reliability analyses are employed to quantify the effect of input data uncertainty.

\subsection{Single or distinct partial factors for variable actions?}

First, the effect of using a single $\left(\gamma_{Q}\right)$ or distinct $\left(\gamma_{I}, \gamma_{S}, \gamma_{W}\right)$ partial factor for variable actions is analyzed. In the current Eurocode specifications, the same partial factor is recommended for snow, imposed and wind actions. The calib- ration results - comparing the two alternatives - are presented in Fig. 3 and in Fig. 4 for reliability indices and for resistances respectively. A heading of each subplot identifies the settings: (1) single or distinct partial factors for variable actions; (2) constant or linearly varying partial factor for variable actions; (3) symmetric or asymmetric objective function. $O_{\text {sym/asym }}$ is the minimum of a respective objective function.
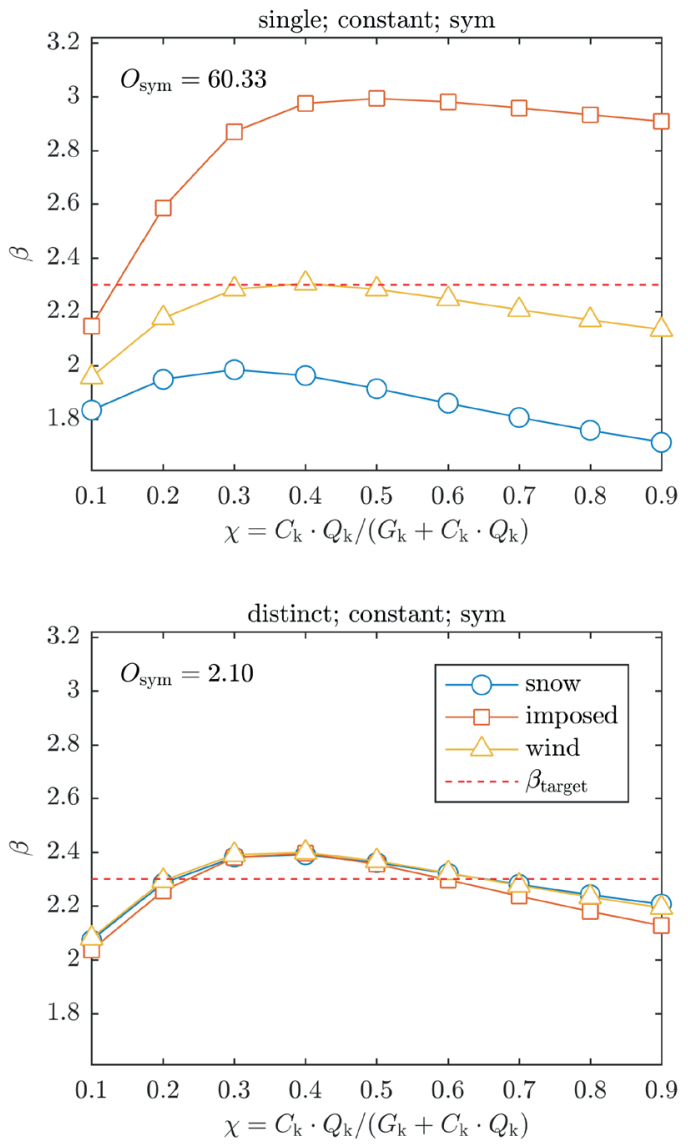

Fig. 3 Reliability indices $(\beta)$ obtained using calibrated partial factors

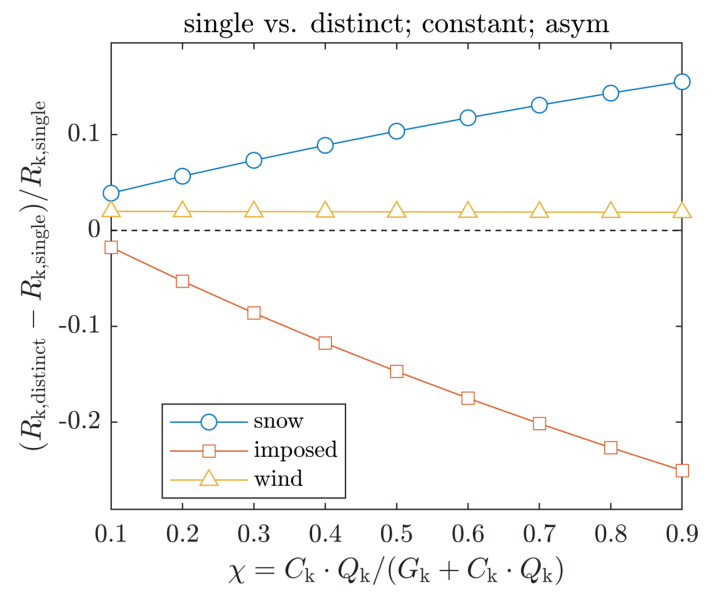

Fig. 4 Ratio of required characteristic resistances obtained by partial factor-based design using calibrated partial factors 
Table 5 Summary of calibration results $\left(t_{\text {ref }}=50\right.$ years $)$

\begin{tabular}{|c|c|c|c|c|c|c|c|c|c|c|}
\hline & & & & & ptimizatio & & & & Expert & dgement \\
\hline \multirow{5}{*}{ 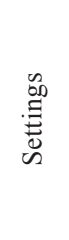 } & $\beta_{\mathrm{t}}$ & 2.3 & 2.3 & 2.3 & 2.3 & 2.3 & 3.8 & 3.8 & 2.3 & 3.8 \\
\hline & single/ distinct $\gamma_{Q}$ & single & distinct & single & single & distinct & single & distinct & distinct & distinct \\
\hline & const./linear $\gamma_{Q}$ & const. & const. & linear & const. & const. & const. & const. & const. & const. \\
\hline & obj. fun. & sym. & sym. & sym. & asym. & asym. & sym. & sym. & sym. & sym. \\
\hline & $\gamma$ selection & a) & a) & a) & a) & a) & b) & c) & NA & NA \\
\hline \multirow{5}{*}{ 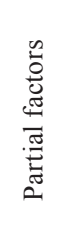 } & $\gamma_{s}$ & 1.50 & 1.49 & $0.89-1.79$ & 1.50 & 1.50 & 2.00 & 2.33 & 1.50 & 2.40 \\
\hline & $\gamma_{I}$ & $"$ & 0.93 & $"$ & $"$ & 0.94 & $"$ & 1.60 & 1.00 & 1.60 \\
\hline & $\gamma_{W}$ & $"$ & 1.31 & $"$ & $"$ & 1.31 & $"$ & 2.08 & 1.30 & 2.10 \\
\hline & $\gamma_{G}$ & 1.13 & 1.01 & 1.38 & 1.05 & 1.00 & 1.11 & 1.13 & 1.05 & 1.05 \\
\hline & $\gamma_{\mathrm{M}}$ & 1.01 & 1.18 & 0.93 & 1.11 & 1.18 & 1.23 & 1.22 & 1.15 & 1.25 \\
\hline \multirow{4}{*}{ 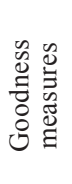 } & $O$ & 60.3 & 2.10 & 53.9 & 339 & 22.2 & 45.16 & 4.95 & 5.83 & 7.85 \\
\hline & weighted mean $\beta$ & 2.32 & 2.30 & 2.33 & 2.57 & 2.31 & 3.81 & 3.80 & 2.35 & 3.81 \\
\hline & weighted std $\beta$ & 0.448 & 0.084 & 0.423 & 0.436 & 0.085 & 0.388 & 0.128 & 0.130 & 0.161 \\
\hline & $\min / \max \beta$ & $1.71 / 2.99$ & $2.04 / 2.40$ & $1.76 / 3.16$ & $2.99 / 3.22$ & $2.08 / 2.42$ & $3.23 / 4.41$ & $3.38 / 3.97$ & $2.10 / 2.58$ & $3.13 / 3.98$ \\
\hline
\end{tabular}

a) Partial factor set with snow partial factor closest to 1.5 .

b) Partial factor set with snow partial factor closest to 2.0.

c) Partial factor set with resistance and permanent partial factors closest to the calibrated resistance (1.15) and permanent (1.05) partial factors obtained with the same settings but $\beta_{\mathrm{t}}=2.3$. The closeness is measured as the sum of the squared differences of partial factors.

NA - not applicable.

The results in Fig. 3 indicate that distinct variable action partial factors significantly outperform the single partial factor. The deviation is quantified by the minimum value of the objective function, which is about 30times smaller for the distinct case.

The characteristic resistance required to reach economic design utilization $\left(R_{\mathrm{d}}=E_{\mathrm{d}}\right)$ in partial factor-based design using the optimized partial factors are compared in Fig. 4. Comparison of the ratio of these resistances for the single and distinct cases reveals considerable $(<25 \%)$ savings (negative change) for the case with leading wind load combination when the distinct partial factors are used. The increase for leading snow and imposed load cases is attributed to the fact that the single partial factor-based design yields a lower reliability level than the target, and also lower than that obtained by the distinct partial factors. Thus, this increase provides no argument against the distinct partial factors as it stems from the correction of insufficient reliability level.

The single and distinct cases are further comparable in terms of calibrated and selected partial factors in Table 5. Wind action has a considerably lower partial factor (1.31) for the distinct case than for the single case (1.50). The selected partial factor for an imposed load is even lower (0.93) - this is attributable to the definition of its characteristic value, which is associated with a $99.5 \%$ fractile of the 5-year maxima distribution (Table 3). This demonstrates the advantage of providing additional free parameters to the calibration.
The indicated partial factors belong to a single set selected by the authors. There is a multitude of solutions with the same performance quantified in terms of an objective function value and achieved reliability level. Results presented in terms of reliability indices and required characteristic values are independent of a particular set of optimum partial factors, as long as the objective function values are equal. These observations are valid for all further analyses including interval representations of reliability indices.

For the distinct partial factors, the analysis is repeated with the $W_{2}$-weights given in Table 2. The changing of the weights has negligible effect on the obtained partial factors $(<5 \%)$. Hence $W_{1}$-weights are considered representative and are the only ones used in further calculations.

\subsection{Symmetric or asymmetric objective function?}

It is shown in Fig. 3 that the symmetric objective function might yield undesired negative deviations from the target reliability. Thus, the performance of an asymmetric objective function proposed by Hansen and Sørensen [11] is investigated in this sub-section. This function penalizes designs leading to insufficient reliability levels more progressively when compared to the benefits associated with conservative designs. The trends of reliability indices are very similar to those displayed in Fig. 3. Negligible differences between the symmetric and asymmetric objective 
functions are further demonstrated by the partial factors and goodness measures given in Table 5. When the distinct partial factors are adopted, the largest difference in the ratio of required characteristic resistances - symmetric to asymmetric - is less than $5 \%$.

It can thus be concluded that the asymmetry of an objective function has negligible effect on the calibrated partial factors and associated reliability levels. However, this conclusion applies only to the cases where reliability indices deviate just slightly from the target level, $|\Delta \beta|<0.5$ in most cases.

\subsection{Constant or linearly varying partial factors for variable actions?}

The improvement provided by the linearly varying partial factor, given in equation (4) for a variable load, is further investigated for the alternative of a single partial factor, i.e. keeping the same factor for all types of variable loads. The trends of reliability indices with the load ratio $\chi$ are plotted in Fig. 5. It appears that the use of the $\gamma_{Q}$ factor varying according to equation (4) reduces the value of the objective function by about $10 \%$. The ratio of required characteristic resistances - for the alternatives with $\gamma_{Q}$ dependent to independent of $\chi$ - suggests savings less than 4\%. Again, the partial factors presented in Table 5 are for a single set of solutions selected by the authors.

Hence, the limited numerical results in Fig. 5 suggest that the simpler design format outweighs the moderate gain in reliability performance and that the partial factors independent of $\chi$ can be recommended for variable actions. However, this finding needs to be verified by further studies.

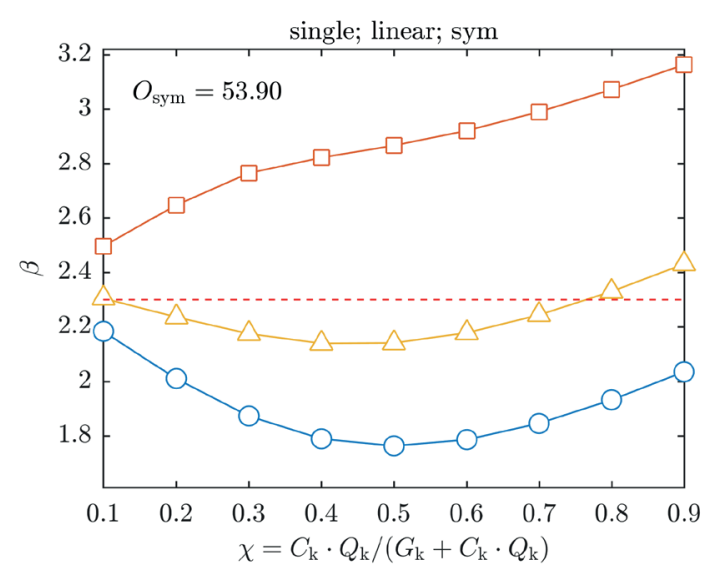

Fig. 5 Reliability indices $(\beta)$ obtained using calibrated partial factors. Single, linearly varying partial factor for variable actions.

\subsection{The effect of target reliability}

EN 1990 [1] specifies a target reliability index of 3.8 for medium failure consequences and a 50-year reference period (Table 1). The results summarized in Table 5 indicate the tendencies of $\gamma_{S}, \gamma_{I}, \gamma_{W}, \gamma_{G}$ and $\gamma_{\mathrm{M}}$ similar to those obtained for $\beta_{\mathrm{t}}=2.3$, though significantly larger values are required to reach the Eurocode target.

\subsection{Selection of partial factors}

An indefinite number of sets of partial factors, minimizing an objective function value, can be obtained by optimization. These sets can be accompanied by goodness-offit measures including objective function value, weighted mean and weighted standard deviation of reliability index, and minima and maxima of values, considering the weights $(w)$ given in Table 2 . For each scenario given in
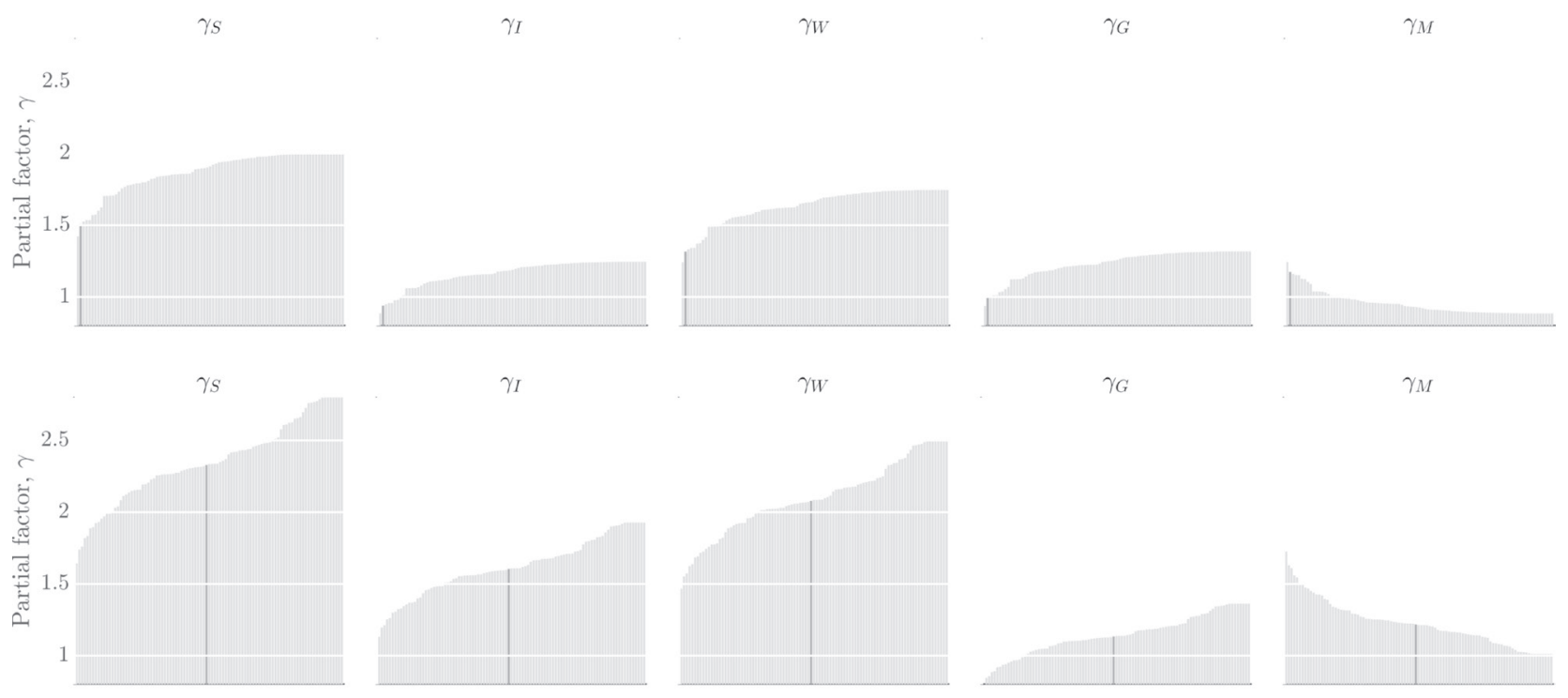

Fig. 6 Sets of partial factors yielding the same objective function value for $\beta_{\mathrm{t}}=2.3$ (top) and for $\beta_{\mathrm{t}}=3.8$ (bottom). Partial factors in the same position are in the same set; the selected set of partial factors coloured in black. All results are for a 50 -year reference period 
Table $5\left(\beta_{\mathrm{t}}, t_{\text {ref }}\right.$, single or distinct $\gamma_{Q}$ etc.), at least 20 optimizations are completed with a different initial value of partial factors which typically yield a different set of partial factors, but the same objective function value.

For $\beta_{\mathrm{t}}=2.3$ and 3.8, the set for which the partial factor for snow load is closest to 1.5 and 2.0 respectively is selected to reduce the disturbance between the proposed and current partial factors. As argued in the previous sub-sections, the set of distinct $\gamma_{S}, \gamma_{I}$ and $\gamma_{W}$ factors independent of $\chi$ is further considered along with the symmetric objective function; the sets of partial factors with the selected values are illustrated in Fig. 6 (a 50-year reference period, top $-\beta_{\mathrm{t}}=$ 2.3 , and bottom $\beta_{\mathrm{t}}=3.8$ ). It appears that the same reliability level can be achieved by markedly different partial factors. For instance for $\beta_{\mathrm{t}}=3.8$, the plausible solutions cover the following ranges of the partial factors:

- $1.6<\gamma_{S}<2.8$

- $1.1<\gamma_{I}<1.9$

- $1.5<\gamma_{W}<2.5$

- $0.8<\gamma_{G}<1.4$

- $1.0<\gamma_{\mathrm{M}}<1.7$
Appreciating the imprecision related to basic variables in practical applications, the calibrated partial factors are finally adjusted based on the expert judgement of the authors (Table 5). It can be demonstrated by goodnessof-fit measures that the adjusted partial factors negligibly impair the performance with respect to associated reliability levels (compare the grey columns in Table 5).

As a final step, to evaluate and to visualize the performance of the calibrated and adjusted partial factors, reliability index intervals are computed using the interval inputs for the parameters of the probabilistic models (Table 3). The intervals of reliability indices obtained using the partial factors given in Table 5 based on expert judgement and $\beta_{\mathrm{t}}=2.3$ are shown in Fig. 7. It is shown that the intervals are quite similar for each of the variable actions, unanimously shrinking with an increasing load ratio. The largest interval width is about 1.50 while the average width is 1.1. This is indicative of the importance of uncertainty in input parameters that is typically neglected in code calibrations.
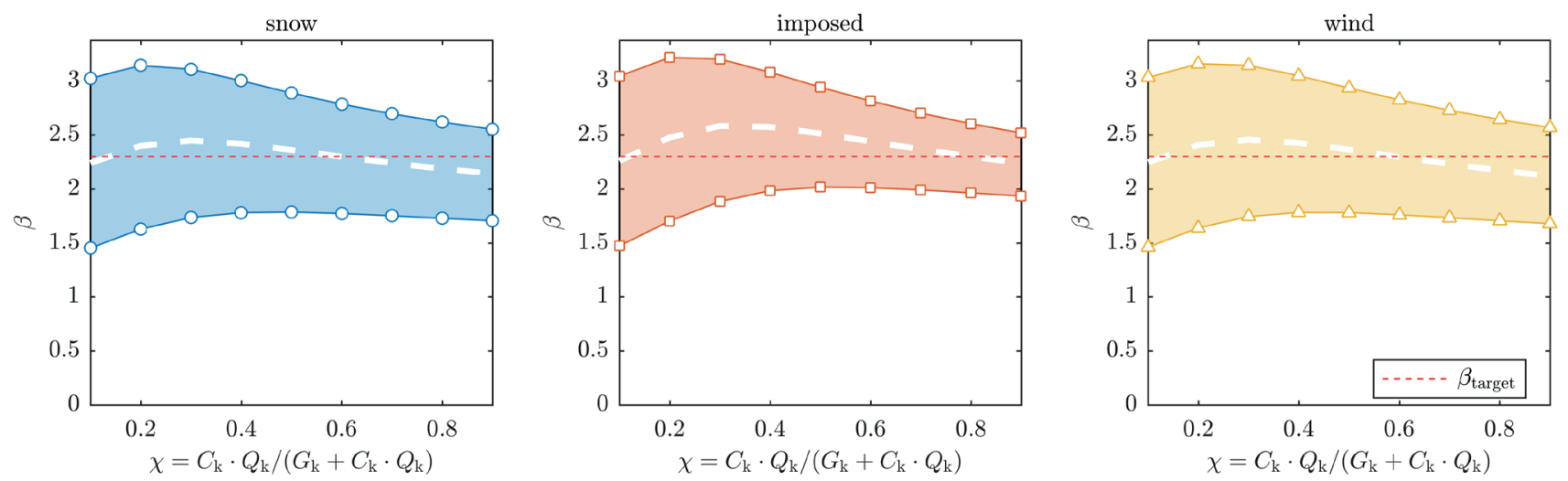

Fig. 7 Intervals of reliability indices obtained using the partial factors given in Table 5 (expert judgement; $\beta_{\mathrm{t}}=2.3$; the dashed lines correspond to the reliability indices obtained using the midpoints of the intervals given in Table 3 )
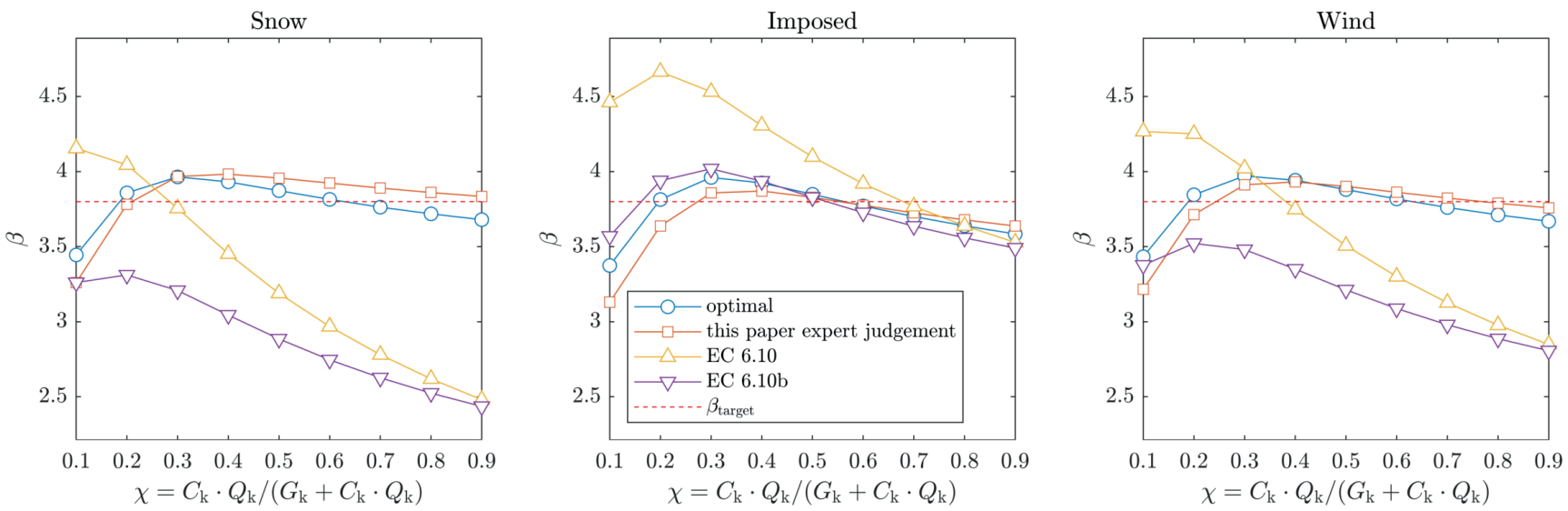

Fig. 8 Variation of reliability index $\beta$ with load ratio $\chi$ for a reference period of 50 years and the target level of 3.8 


\subsection{Benefit gained by applying the methodology}

In order to demonstrate possible gain by applying of the presented methodology, a comparison with the current Eurocode partial factors is provided by focusing on mean and dispersion of the reliability levels associated with the design based on different partial factors. In Fig. 8 the variation of reliability index $\beta$ with load ratio $\chi$ is shown for a reference period of 50 years and the target level of 3.8. It appears that:

- The current Eurocode factors do not ensure the target reliability and lead to very unbalanced reliability levels in comparison to the optimized partial factors (labelled in Fig. 8 as "optimal" and "this paper - expert judgement").

- The optimized partial factors provide for the weighted of reliabilities close to the target level and has much smaller scatter compared to the Eurocode factors.

Averaging over all the variable action cases under consideration for $\beta_{\mathrm{t}}=3.8$, the presented methodology (expert judgement) provides about 3.7-times smaller weighted standard deviation than that obtained for combination rule 6.10 and about 2.8 times smaller standard deviation than that for $6.10 \mathrm{~b}$. The weighted reliability index for the optimized partial factors is 3.8 while the 6.10 and $6.10 \mathrm{~b}$ formulas lead to averaged reliability indices of 3.6 and 3.3, respectively.

It should be emphasized that the results are conditioned on the analyzed cases and adopted assumptions.

\section{Discussion}

\subsection{Comparison with other studies}

The submitted study attempts to provide an overall methodology, the application of which is illustrated by a numerical example. Some of the drawn conclusions are deemed to be well justified and provide the basis for recommendations for future calibrations; for instance on the choices between single or distinct partial factors $\gamma_{Q}$ for variable actions, constant or linearly varying $\gamma_{Q}$, and symmetric or asymmetric objective functions. The study also highlights the main difficulties associated with calibrations:

1. Formulating representative models for basic variables

2. Selecting amongst a broad range of solutions minimizing the objective function.

However, the obtained values of the partial factors (Table 5) should be considered as indicative only since the choices related to the aforementioned must be based on a broad consensus amongst reliability experts. The ranges of the optimum partial factors obtained in Subsection 5.6 are in agreement with those reported previously; for instance focusing on the partial factors for the variable actions and for $\beta_{\mathrm{t}}=3.8$ :

- fib bulletin [59] indicated $1.5<\gamma_{S}<2.3,1.0<\gamma_{I}<1.7$, and $1.4<\gamma_{W}<2.2$ for various climates and types of buildings;

- Holicky and Sykora [14] proposed $2<\gamma_{S}<3$ for $\chi \geq$ 0.2 .

Beck and Souza [25] considered a lower target of 3.0 and various combinations of variable actions; as an example they obtained $1.7<\gamma_{I}<1.9$ for $\chi>0.67$ and smaller contributions of wind action. Similarly they derived $\gamma_{W} \approx$ 2 for $\chi>0.67$ and smaller contributions of imposed load.

Baravalle and Köhler [84] considered annual reference period as a basis for the reliability analysis and optimization $[76,81]$ and obtained $1.6<\gamma_{W}<1.8$.

The annual reference period was also adopted in the recent studies of CEN TC250/ SC10/ WG1 - the working group focused on calibrating partial factors within the revision of EN 1990. Assuming $\gamma_{\mathrm{M}}=1.0$ for steel structural members, WG1 tentative results suggest $\gamma_{G} \approx 1.2$ and $\gamma_{W} \approx$ $\gamma_{S} \approx \gamma_{I} \approx 1.65$. These indications reasonably match those provided in Table 5 (and in Table 6 in 7 Conclusions) - the increased partial factor for permanent action compensates for the reduced material factor. The lower partial factors for wind and snow are attributable to a higher positive bias for the wind pressure model and lower CoVs, respectively, considered by WG1.

\subsection{Limitations of the presented study}

The presented study provides a limited insight into the broad scope of calibrations of reliability elements such as partial and combination factors for normative documents:

1. Partial factors for other construction materials such as concrete, timber, masonry, glass, aluminium, soils etc. might require slightly extended considerations due to possibly significant time-dependent or spatial variability effects; see e.g. [85, 86, 87, 88].

2. Also the range of variable actions under investigation here is far to be complete - other actions for permanent and transient design situations include water and thermal actions, imposed loads in industrial buildings or crane loads. Whenever relevant, time-dependent load changes - for instance due to climate or environmental changes - need considerations beyond the presented methodology. 
3. Though an attempt is made to establish the study on generic models of basic variables for steel members, the distinct features of various failure modes such as bending, shear or buckling should be taken into account in separate calibrations to indicate appropriate values of partial factors.

4. Only component failure modes are analyzed in this study, while system behavior may provide for an additional reliability margin.

5. A single variable action is considered as a special issue of the reliability theory - combination of several variable actions is beyond the scope of this contribution. Previous studies revealed that the combination factors accepted in Eurocodes are often conservative and lower reliability levels were commonly obtained for structures exposed to a single variable action compared to structures exposed to the effects of several variable actions [13].

6 . For brevity, the simplified combination rule Eq. 6.10 in EN 1990 [1] - is adopted in the study. The use of the twin expressions $6.10 \mathrm{a}$,b would likely lead to slightly better balanced reliability levels than those provided in Fig. 2, 3, 5 and 7; see [12, 13].

7. The uncertainty in the parameters of probabilistic models, expressed in Table 3 by intervals, partially stems from spatial variation of actions and from differences across the range of steel classes, joints, structural members, failure modes and structural systems. Such uncertainty is unavoidable in codification where provisions intend to cover most practical situations. However, the interval representation does not allow unambiguous calibration, as it yields to intervals of reliability index and consequently to intervals of objective function values, while classical optimization requires a scalar valued function. This issue is resolved here by taking the mid values of the input intervals to run the calibration. A more prudent approach would use lower bounds of reliability index intervals. A more involved and theoretically sounder approach would treat this uncertainty in a probabilistic manner by assigning probability distributions to parameters appreciating the differences given above.

This contribution provides a methodology and some input data, and identifies the topics that should be treated within further research. Full-scale, comprehensive calibrations should incorporate the aforementioned aspects.

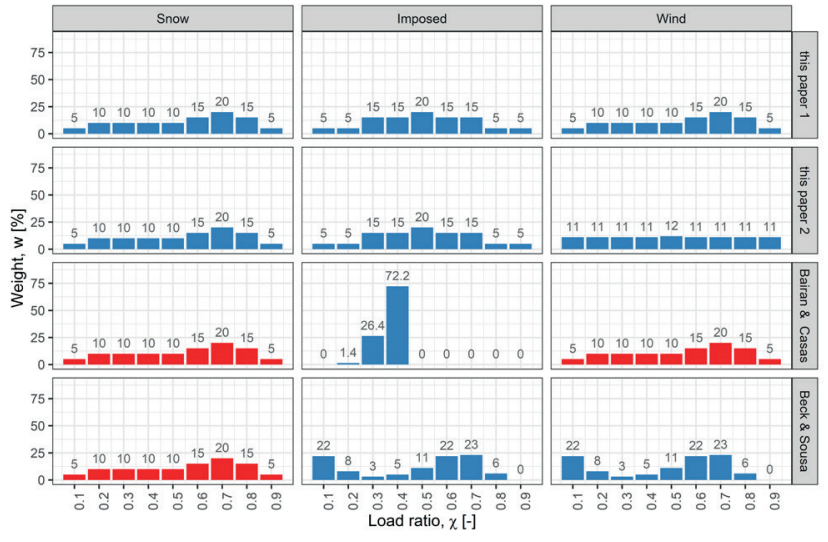

Fig. 9 Weights for different load ratios considered in this study and by Beck and Sousa [25] for steel members, and by Bairan and Casas [80] for reinforced concrete beams and slabs in buildings (the histograms in red indicate the cases where a variable load was not considered in a referenced study - the weights $W_{1}$ were applied in the calibration procedure to compare the presented methodology with the previous study)

\subsection{Effect of weights}

In Subsection 2.3.3 the weights of different design situations - different $\chi$-ratios are selected on the basis of previous publications, prenormative research, and empirical experience $[55,77]$. For steel structural members, the sensitivity of optimized partial factors to uncertainty in these weights is then found small or even negligible in Subsection 5.2.

However, it must be emphasized that the weights are strongly material- and structural member-dependent $[55,77]$ :

- Low $\chi$-ratios are more common for concrete, masonry and geotechnical structures, underground structures, and substructures of long-span bridges etc.

- High $\chi$-ratios are typical for glass and aluminium structures, storage and industrial buildings, crane girders, main structural girders of short-span bridges, secondary members of bridges.

Bairan and Casas [80] assumed in their calibrations of reinforced concrete beams and slabs exposed to shear the weights provided in Fig. 9. With dominating $\chi$-ratios around 0.3 and 0.4 , these weights are distinctly different from those adopted in this study.

Despite these significant differences, calibration for the imposed load based on Bairan and Casas's weights leads very similar partial factors. For $\beta_{\mathrm{t}}=3.8$, the following values (rounded up to 0.05) are obtained: $\gamma_{I}=1.5$ (whereas in the present it is 1.6; see Table 5 - expert judgement); $\gamma_{G}=$ 1.05 (1.05); and $\gamma_{M}=1.25$ (1.25). The effect is thus negligible in the light of the vast range of plausible solutions. When the target reliability reduces to 2.3 , the effect of the change in weights entirely vanishes. 
Also displayed in Fig. 9 are the weights considered by Beck and Sousa [25] for the combinations of a permanent and single variable action. These weights are based on [55] and are thus close to those adopted here, with somewhat higher estimates for low and high $\chi$-values - 0.1 and 0.6-0.7, respectively. Calibration based on Beck and Sousa's weights lead to the same optimum factors as those in Table 5.

\section{Conclusions}

The contribution provides a methodology and input data for calibrating partial factors for structural design at the Ultimate Limit States.

1. Methodology. The iterative procedure consists of four steps - partial factor-based design, development of probabilistic models on the basis of characteristic values, probabilistic reliability analysis, and optimization. Despite its limitations (Subsection 6.2), the methodology makes it possible to:

- Calibrate the partial factors considered in the design - commonly partial factors for material $\gamma_{\mathrm{M}}$, permanent loads $\gamma_{G}$, and variable actions $\gamma_{Q}$.

- Quickly analyse different failure modes, design rules for load combinations, and alternative models for basic variables; hence it is appropriate for extended calibrations.

2. Input data

- As the probabilistic models of basic variables have a substantial effect on calibrated partial factors, systematic and detailed investigations of such models are needed to provide realistic inputs. Calibration results should be always supplemented by full information on assumed probabilistic models.

- The probabilistic models proposed in Table 3 provide indicative statistical characteristics of basic variables, deemed to be relevant particularly for current European design and execution procedures.

- Models of basic variables should always be adjusted taking into account regional or national specifics such as production technologies, quality control methods or climatic conditions; the presented methodology is sufficiently flexible to provide for such adjustments and updates when new information becomes available.

- Besides the typical probabilistic representation of uncertainty (and variability) of basic variables, intervals may be used when it is difficult to assign a probabilistic distribution to a basic variable or a parameter, such as to the coefficients of variation of variable actions in Table 3. Through interval representation, the methodology allows considering a larger level of ignorance than common probabilistic models. Hybrid probabilistic-interval reliability analysis then provides a tool to propagate such uncertainties into reliability index estimates.

3. Numerical application of the proposed methodology and probabilistic models reveals that:

- The partial factors recommended in the current standards provide for a lower reliability level than that indicated in EN 1990; reliability indices around 2.3 are obtained for a 50-year reference period. Such a low reliability level might be attributed to "hidden safety" in the time-invariant components of climatic actions, increasing use of better calculation models (possibly associated with reduced model uncertainties), and additional requirements on structural robustness [69].

- Partial factors for variable actions - independent of the ratio of permanent and variable actions - can be taken into account. The simpler design format outweighs the minor improvement gained by using the partial factors dependent on the load ratio.

- Different values should be considered for the partial factors for imposed, wind and snow loads $\left(\gamma_{I}, \gamma_{W}\right.$ and $\gamma_{S}$, respectively), taking into account different uncertainties in their load effect models.

- When the distinction between $\gamma_{I}, \gamma_{W}$ and $\gamma_{S}$ is made, calibrations based on symmetric and asymmetric objective functions lead to similar results.

- Table 6 summarizes the main numerical outcomes of the study - the calibrated partial factors for the target reliabilities 2.3 and 3.8, and a reference period of 50 years.

The presented methodology provides about 3.7-times smaller weighted standard deviation than that obtained for EN 1990 combination rule 6.10 and about 2.8 times smaller standard deviation than that for $6.10 \mathrm{~b}$. The weighted reliability index for the optimized partial factors is 3.8 while the 6.10 and $6.10 \mathrm{~b}$ formulas lead to averaged reliability indices of 3.6 and 3.3 , respectively.

Table 6 Calibrated partial factors for different target reliabilities and a reference period of 50 years

\begin{tabular}{lccccc}
\hline $\begin{array}{l}\text { Target } \\
\text { level }\end{array}$ & Snow & Imposed & Wind & Permanent & $\begin{array}{c}\text { Material } \\
\text { (steel) }\end{array}$ \\
\hline 2.3 & 1.5 & 1.0 & 1.3 & 1.05 & 1.15 \\
3.8 & 2.4 & 1.6 & 2.1 & 1.05 & 1.25 \\
\hline
\end{tabular}


Subsequent comprehensive calibrations focused on the Ultimate Limit States STR should take into account additional aspects that are beyond the scope of this study:

- Partial factors for other construction materials (concrete, timber, masonry, soils or glass), other types of actions (thermal and water actions, imposed loads in industrial buildings), and other types of structures in particular road and railway bridges;

- The distinct features of failure modes such as bending, shear or buckling;

- System behavior;

- Combination of several variable actions and calibration of combination factors; and

- Use of combination rules other than Eq. 6.10 in EN 1990.

The methodology can be also utilized to calibrate partial factors on other design situations where a different character of basic variables and different (commonly lower) target levels need to be taken into account; examples include Serviceability Limit States for crack width control of liquid retaining structures [89], seismic, fire or accidental design situations.

Appreciating the limited scope of the presented study in respect of considered models and input parameters and to facilitate further studies, the computer code of the presented methodology is made available in the following repository: github.com/rozsasarpi/Code-calibration-Belarus

\section{Acknowledgements}

The presented study has been partly supported by the Czech Ministry of Education, Youth and Sports under Grant LTT18003 and by the Ministry of Industry and Trade of the Czech Republic under Grant FV 20585. The second author has completed a substantial part of his contribution at the Department of Structural Engineering, Budapest University of Technology and Economics, Budapest, Hungary, the support of which is appreciated. The contributions of Prof. Tur V. (Brest State Technical University) and Prof. Martynov Y. (Belarusian National Technical University), providing background information related to appropriate probabilistic models, are acknowledged.

\section{References}

[1] European Committee For Standardization, "EN 1990. Eurocode Basis of structural design", CEN, Brussels, 2002.

[2] Diamantidis, D. "Probabilistic Assessment of Existing Structures", RILEM Publications, Cachan, France, 2001.
[3] Luechinger, P., Fischer, J., Chrysostomou, C., Dieteren, G., Landon, F. et al. "New European Technical Rules for the Assessment and Retrofitting of Existing Structures", Publications Office of the European Union, Luxembourg, 2015.

https://doi.org/10.2788/095215

[4] Holicky, M. "Optimisation of the target reliability for temporary structures", Civil Engineering and Environmental Systems, 30(2), pp. 87-96, 2013.

https://doi.org/10.1080/10286608.2012.733373

[5] Steenbergen, R. D., Sykora, M., Diamantidis, D., Holicky, M., Vrouwenvelder, T. "Economic and Human Safety Reliability levels for Existing Structures", Structural Concrete, 16(3), pp. 323-332, 2015. https://doi.org/10.1002/suco.201500022

[6] Sykora, M., Diamantidis, D., Holicky, M., Jung, K. "Target Reliability for Existing Structures Considering Economic and Societal Aspects", Structure and Infrastructure Engineering, 13(1), pp. 181-194, 2016.

https://doi.org/10.1080/15732479.2016.1198394

[7] International Organization for Standardization, "ISO 2394. General Principles on Reliability for Structures", Geneve, Switzerland, 2015.

[8] Allen, D. E. "Limit States Design - A Probabilistic Study", Canadian Journal of Civil Engineering, 2(1), pp. 36-49,1975. https://doi.org/10.1139/175-004

[9] Ellingwood, B., MacGregor, J. G., Galambos, T. V., Cornell, C. A. "Probability Based Load Criteria: Load Factors and Load Combinations", Journal of the Structural Division, 108(5), pp. 978-997, 1982. [online] Available at: https://www.researchgate. net/publication/279566120_Probability_Based_Load_Criteria_ Load_Factors_and_Load_Combinations [Accessed: 2101 2019]

[10] Vrouwenvelder, A. C. W. M., Siemes, A. J. M. "Probabilistic calibration procedure for the derivation of partial safety factors for the Netherlands building codes", Heron, 32(4), pp. 9-29, 1987. [online] Available at: https://www.researchgate.net/publication/42603578_ Probabilistic_calibration_procedure_for_the_derivation_of_ partial_safety_factors_for_the_Netherlands_building_codes [Accessed: 2101 2019]

[11] Friis-Hansen, P., Sørensen, J. D. "Reliability-based code calibration of partial safety factors", Presented at JCSS Workshop on Reliability Based Code Calibration, Zurich, Switzerland, March 21-22, 2002.

[12] Holický, M., Retief, J. V. "Reliability assessment of alternative Eurocode and South African load combination schemes for structural design", Journal of the South African Institution of Civil Engineering, 47(1), pp. 15-20, 2005. [online] Available at: https:// saice.org.za/downloads/journal/vol47-1-2005/civileng_v47_n1_c. pdf [Accessed: 2101 2019]

[13] Gulvanessian, H., Holicky, M. "Eurocodes: using reliability analysis to combine action effects", Proceedings os the Institution of Civil Engineers - Structures and Buildings, 158(4), pp. 243-252, 2005. https://doi.org/10.1680/stbu.2005.158.4.243

[14] Holicky, M., Sykora, M. "Partial Factors for Light-Weight Roofs Exposed to Snow Load", Supplement to Proc. ESREL 2009, pp. 23-30, 2009. 
[15] Melchers, R. E., Beck, A. T. "Structural Reliability Analysis and Prediction”, John Wiley \& Sons Ltd., Chichester, England, 2017. https://doi.org/10.1002/9781119266105

[16] Holicky, M., Diamantidis, D., Sykora, M. "Determination of Target Safety for Structures", presented at International Conference on Applications of Statistics and Probability, Vancouver, Canada, July, 12-15, 2015.

https://doi.org/10.14288/1.0076258

[17] JCSS, "JCSS Probabilistic Model Code", Joint Committee on Structural Safety, 2018. [online] Available at: https://www.jcss.byg. dtu.dk/Publications/Probabilistic_Model_Code [Accessed date: 1701 2019]

[18] Martynov I., Nadolski V. "The statistical parameters of basic variables in the resistance model of steel element", Architecture and construction science, 1, 2(18, 19), pp. 39-41, 2014. (in Russian)

[19] Baldin, V. A., Uritsky, M. R. "Security of normative and design resistance of mild steel for construction steel", Industrial construction. 6, pp. 19-21, 1978. (in Russian)

[20] Sýkora, M. "Reliability Analysis of a Steel Frame", Acta Polytechnica, 42(4), pp. 27-34, 2002. [online] Available at: https:// ojs.cvut.cz/ojs/index.php/ap/article/view/370 [Accessed date: 2101 2019]

[21] Kala, Z. "Influence of partial safety factors on design reliability of steel structures - probability and fuzzy probability assessments", Journal of Civil Engineering and Management, 13(4), pp. 291-296, 2007.

https://doi.org/10.1080/13923730.2007.9636449

[22] Holický, M. "Safety design of lightweight roofs exposed to snow load", WIT Transactions on Engineering Sciences, 58(7), pp. 51-57, 2007. https://doi.org/10.2495/EN070061

[23] Sýkora, M. Holicky, M. "Reliability-based design of roofs exposed to a snow load", In: Reliability Engineering - Proceedings of the International Workshop on Reliability Engineering and Risk Management IWRERM 2008, Shanghai, China, 2008, pp. 183-188.

[24] Sykora, M., Holicky, M. "Comparison of load combination models for probabilistic calibrations", In: Applications of Statistics and Probability in Civil Engineering, CRC Ptrss, Boca Raton, Florida, USA, 2011, pp. 977-985.

[25] Beck, A. T., de Souza, Jr., A. C. "A first attempt towards reliability-based calibration of Brazilian structural design codes", Journal of the Brazilian Society of Mechanical Sciences and Engineering, 32(2), pp. 119-127, 2010. https://doi.org/10.1590/S1678-58782010000200004

[26] Honfi, D., Mårtensson, A., Thelandersson, S. "Reliability of beams according to Eurocodes in serviceability limit state", Engineering Structures, 35 pp. 48-54, 2012.

https://doi.org/10.1016/j.engstruct.2011.11.003

[27] Gulvanessian, H., Holicky, M. "Reliability based calibration of Eurocodes considering a steel member. Workshop on Reliability Based Code Calibration", presented at Workshop on Reliability Based Code Calibration, Zurich, Switzerland, March, 21-22, 2002.
[28] Melcher, J., Kala, Z., Holický, M., Fajkus, M., Rozlívka, L. "Design characteristics of structural steels based on statistical analysis of metallurgical products", Journal of Constructional Steel Research, 60(3), pp. 795-808, 2004.

https://doi.org/10.1016/S0143-974X(03)00144-5

[29] Nadolski, V., Sykora, M. "Uncertainty in Resistance Models for Steel Members", Transactions of the VSB - Technical University of Ostrava, Civil Engineering Series, 14(2), pp. 26-37, 2014. https://doi.org/10.2478/tvsb-2014-0028

[30] Markowski , D. M. "Calibration values of reinforced concrete structures, taking into account security settings defined indicators of reliability", PhD Thesis, Brest State Technical University, 2009. (in Russian)

[31] Holicky, M., Markova, J. "Calibration of Reliability Elements for a Column". presented at Workshop on Reliability Based Code Calibration: Press Release, Zurich, Switzerland, March, 21-22, 2002.

[32] NKB/SAKO, "Basis of design of Structures. Proposal for modification of Partial Safety Factorsin Eurocodes, 1999:01 E", Nordic Council of Ministers, Oslo, Norway, 1999.

[33] Tur, V. V., Markovskij, D. M. "Calibration combination factors for the action in the calculation of reinforced concrete structures in the permanent and accidental design situations", Construction Science and Engineering, 23(2), pp. 32-48, 2009. (in Russian)

[34] Gordeev, V. N., Lantukh-liashenko, A. I., Pashinsky, V. A., Perelmuter, A. V., Pichugin, S. F. "Loads and actions on buildings and structures", Publishers Association of Engineering Universities, Moscow, Russia, 2007. (in Russian)

[35] Rajzer, V. D. "Methods of reliability theory in problems of standardization of design parameters of building structures", M. :Strojizdat, 192 c. 1986. (in Russian)

[36] Bulychev, A. P. "Live loads on structures building trade", Structural Mechanics and Calculation of Structures, 3, pp. 57-59, 1989. (in Russian)

[37] Avramenko, P. V. "Loads on floors of multistory office buildings", Building mechanics and calculation sooruzheniy. No. 1. pp. 67-71. 1980. (in Russian)

[38] Tur, V., Valuev V., Derechennik S., Meshik O., Voskoboynikov I. "Normalization snow loads for the territory of the Republic of Belarus", Construction Science and Technology, pp. 27-45, 2008. (in Russian)

[39] European Committee For Standardization, "EN 1991-1-3. Eurocode 1: Actions on structures - Part 1-3: General actions; Snow loads", CEN: Brussels, Netherlands, 2003.

[40] International Organization for Standardization, "ISO 4355. Basis for design of structures - Determination of snow loads on roofs", ISO, Geneve, Switzerland, 2013.

[41] Králik, J. "Comparison of Probabilistic Methods to Solve the Reliability of Structures in ANSYS", In: Proceedings of Conference ANSYS, Pilsen, Czech Republic, 2009, pp. 63-70.

[42] Rozsas, A., Sykora, M. "Model Comparison and Quantification of Statistical Uncertainties for Annual Maxima of Ground Snow Loads", In: Safety and Reliability of Complex Engineered Systems -Proceedings of the European Safety and Reliability Conference ESREL 2015, Zurich, Switzerland, 2015. pp. 2667-2674. 
[43] Rozsas A., Sykora, M. "Effect of Statistical Uncertainties in Ground Snow Load on Structural Reliability", In: Proceedings of IABSE Conference Geneva 2015, Structural Engineering: Providing Solutions to Global Challenges, Geneva, Switzerland, 2015, pp. 220-227. https://doi.org/10.2749/222137815818357142

[44] Chairman of Project Group 2.5 "Eurocodes", "Safety of Structures", [online] http://www.europeanconcrete.eu

[45] Marková, J., Holicky, M. "Calibration of partial factors for design of concrete structures" In: Proceedings of 11th International Conference on Applications of Statistics and Probability in Civil Engineering ICASP11, Zurich, Switzerland, 2011, pp. 986-990.

[46] Chernoivan, A. V. "Normalization of wind loads on buildings and structures for the climatic conditions of the Republic of Belarus", PhD Thesis, Brest State Technical University, 2012. (in Russian)

[47] Sýkora, M., Holický, M., Nadolski, V. "Comparison of the reliability levels provided by Eurocodes and standards of the Russian Federation", In: Proceedings of the European Safety and Reliability Conference ESREL 2013, Amsterdam, Netherlands, 2013, pp. 2637-2644.

[48] Nadolski, V., Holický, M., Sýkora M. "Comparison of the reliability levels provided by Eurocodes and by standards of the Republic of Belarus", Vestnik MGSU, 2, pp. 7-21, 2013.

[49] SNiP II-23-81* "Steel Structures", Moscow, State Construction Committee, Moscow, 1991.

[50] SNiP 2.01.07-85 "Loads and actions", State Construction Committee, Moscow, 1999.

[51] Holicky, M., Sykora, M. "Failures of roofs under snow load: Causes and reliability analysis", In: Fifth Forensic Engineering Congress, Washington, DC, USA, 2009, pp. 444-453.

[52] Rózsás, Á., Vigh, L. G. "On the reliability of steel frames exposed to snow load. Considering the effect of epistemic uncertainty", In: 7th European Conference on Steel and Composite Structures, Eurosteel 2014, Naples, Italy, 2014, pp. 1-6.

[53] MSZ 15021/1-86. "Építmények teherhordó szerkezeteinek erőtani tervezése. Magasépítési szerkeztek terhei", "Design of load bearing structures of buildings. Design loads for buildings" (In Hungarian)

[54] Nocedal, J., Wright S. J. "Numerical Optimization", 2nd ed., Springer Series in Operations Research, Springer Verlag, New York, NY, USA, 2006.

[55] Ellingwood, B. R., Galambos, T. V., MacGregor, J. G., Cornell, C. A. "Development of a probability based load criterion for American national standard A58: building code requirements for minimum design loads in buildings and other structures", U.S. Deptartment of Commerce, National Bureau of Standards, Washington, DC, USA, 1980.

[56] Sørensen, J. D., Hansen, S. O. "Background for Partial Safety Factors in Danish NA to EN 1990", CEN/TC 250/SC 10, number of document N 10, 2016.

[57] Holický, M., Retief, J. V., Viljoen, C. "Partial factors for wind actions considering hidden safety due to time invariant components", In: Insights and Innovations in Structural Engineering, Mechanics and Computation, SEMC 2016, Cape Town, South Africa, 2016, pp. 687-692.
[58] Sanpaolesi L., Currie D., Sims P., Sacré C., Stiefel U. et al. "Scientific support activity in the field of structural stability of civil engineering works: Snow loads", Final Report, Phase I., University of Pisa, Department of Structural Engineering, Pisa, Italy, 1998.

[59] Caspeela, R., Steenbergen, R., Sykora, M. (eds) "Partial Factor Methods for Existing Structures", fib Bulletin, 80, Lausanne, Switzerland, 2016.

[60] Hansen, S. O., Pedersen, M. L., Sørensen, J. D. "Probability based calibration of pressure coefficients", presented at 14th International Conference on Wind Engineering, Porto Alegre, Brazil, June, 21-26, 2015.

[61] Honfi, D. "Serviceability floor loads", Structural Safety, 50 pp. 27-38. 2014. https://doi.org/10.1016/j.strusafe.2014.03.004

[62] Chalk, P. L., Corotis, R. B. "Probability model for design live loads", Journal of the Structural Division, 106(10), pp. 2017-2033, 1980. [online] Available at: https://cedb.asce.org/CEDBsearch/ record.jsp?dockey $=0009784$ [Accessed 2101 2019]

[63] Harris, M. E., Bova, C. J., Corotis, R. B. "Area-dependent processes for structural live loads", Journal of the Structural Division. 107(5), pp. 857-872, 1981. [online] Available at: https://cedb.asce.org/ CEDBsearch/record.jsp?dockey=0010223 [Accessed 2101 2019]

[64] Botha, J. "Probabilistic models of design wind loads in South Africa", PhD Thesis, Stellenbosch University, 2016.

[65] Sadovský, Z., Sýkora, M. "Snow load models for probabilistic optimization of steel frames", Cold Regions Science and Technology, 94, pp. 13-20, 2013. https://doi.org/10.1016/j.coldregions.2013.06.004

[66] ASCE/SEI 7-10. "Minimum design loads for buildings and other structures", American Society of Civil Engineers, Reston, Virginia, U.S.A., 2013. https://doi.org/10.1061/9780784412916

[67] Sýkora, M., Holický, M., Marková, J. "Verification of existing reinforced concrete bridges using the semi-probabilistic approach", Engineering Structures, 56, pp. 1419-1426, 2013. https://doi.org/10.1016/j.engstruct.2013.07.015

[68] Caspeele, R., Sykora, M., Allaix, D. L., Steenbergen, R. "The Design Value Method and Adjusted Partial Factor Approach for Existing Structures", Structural Engineering International, 23(4), pp. 386-393, 2013.

https://doi.org/10.2749/101686613X13627347100194

[69] Agarwal, J., Haberland, M., Holicky, M., Sykora, M., Thelandersson, S. "Robustness of Structures: Lessons from Failures", Structural Engineering International, 22(1), pp. 105-111, 2012. https://doi.org/10.2749/101686612X13216060213635

[70] Sykora, M., Holicky, M., Prieto, M., Tanner, P. "Uncertainties in resistance models for sound and corrosion-damaged RC structures according to EN 1992-1-1." Materials and Structures, 48(10), pp. 3415-3430, 2015. https://doi.org/10.1617/s11527-014-0409-1

[71] Holický, M., Retief, J. V., Sýkora, M. "Assessment of Model Uncertainties for Structural Resistance", Probabilistic Engineering Mechanics, 45, pp. 188-197, 2016.

https://doi.org/10.1016/j.probengmech.2015.09.008 
[72] Tanner, P., Hingorani, R. "Acceptable risks to persons associated with building structures", Structural Concrete, 16(3), pp. 314-322, 2015. https://doi.org/10.1002/suco.201500012

[73] Ghasemi, S. H., Nowak, A. S. "Target reliability for bridges with consideration of ultimate limit state", Engineering Structures, 152 pp. 226-237, 2017.

https://doi.org/10.1016/j.engstruct.2017.09.012

[74] Yanaka, M., Ghasemi, S. H., Nowak, A. S. "Reliability-based and life-cycle cost-oriented design recommendations for prestressed concrete bridge girders", Structural Concrete, 17(5), pp. 836-847, 2016. https://doi.org/10.1002/suco.201500197

[75] Ghasemi, S. H., Nowak, A. S. "Reliability analysis of circular tunnel with consideration of the strength limit state", Geomechanics and Engineering, 15(3), pp. 879-888, 2018. https://doi.org/10.12989/gae.2018.15.3.879

[76] Rackwitz, R. "Optimization - the basis of code-making and reliability verification", Structural Safety, 22(1), pp. 27-60, 2000. https://doi.org/10.1016/S0167-4730(99)00037-5

[77] Sykora, M., Holicky, M., Markova, J., Senberger, T. "Probabilistic Reliability Assessment of Existing Structures (focused on industrial heritage buildings)", 1st ed., CTU Publishing House, Prague, Czech Republic, 2016.

[78] O'Brien, E. J., Schmidt, F., Hajializadeh, D., Zhou, X.-Y., Enright, B., Caprani, C. C., Wilson, S., Sheils, E. "A review of probabilistic methods of assessment of load effects in bridges", Structural Safety, 53 pp. 44-56, 2015.

https://doi.org/10.1016/j.strusafe.2015.01.002

[79] Ghasemi, S. H., Nowak, A. S. "Mean maximum values of non-normal distributions for different time periods", International Journal of Reliability and Safety, 10(2), pp. 99-109, 2016. https://doi.org/10.1504/IJRS.2016.078381

[80] Bairán, J.-M., Casas, J. R. "Safety factor calibration for a new model of shear strength of reinforced concrete building beams and slabs", Engineering Structures, 172 pp. 293-303, 2018. https://doi.org/10.1016/j.engstruct.2018.06.033

[81] Fischer, K., Viljoen, C., Köhler, J., Faber, M. H. "Optimal and acceptable reliabilities for structural design", Structural Safety, 76 pp. 149-161, 2019. https://doi.org/10.1016/j.strusafe.2018.09.002
[82] Spellucci, P. "A New Technique for Inconsistent QP Problems in the SQP Method", Mathematical Methods of Operations Research, 47(3), pp. 355-400, 1998. https://doi.org/10.1007/BF01198402

[83] Tone, K. "Revisions of constraint approximations in the successive QP method for nonlinear programming problems", Mathematical Programming, 26(2), pp. 144-152, 1983. https://doi.org/10.1007/BF02592051

[84] Baravalle, M., Köhler, J. "On the probabilistic representation of the wind climate for calibration of structural design standards", Structural Safety, 70, pp. 115-127, 2018. https://doi.org/10.1016/j.strusafe.2017.10.012

[85] Baravalle, M., Mikoschek, M., Colling, F., Köhler, J. "Calibration of simplified safety formats for structural timber design", Construction and Building Materials, 152, pp. 1051-1058, 2017. https://doi.org/10.1016/j.conbuildmat.2017.06.155

[86] Sørensen, J. D., Svensson, S., Stang, B. D. "Reliability-based calibration of load duration factors for timber structures", Structural Safety, 27(2), pp. 153-169, 2005.

https://doi.org/10.1016/j.strusafe.2004.10.001

[87] Feldmann, M., Kasper, R., Abeln, B., Cruz, P., Belis, J. et al. "Guidance for European Structural Design of Glass Components (JRC Science and Policy Report), Publications Office of the European Union, Ispra, Italy, 2014.

[88] Badalassi, M., Biolzi, L., Royer-Carfagni, G., Salvatore, W. "Safety factors for the structural design of glass", Construction and Building Materials, 55 pp. 114-127, 2014.

https://doi.org/10.1016/j.conbuildmat.2014.01.005

[89] Lenner, R., Viljoen, C., van Nierop, S. "A comparative study of target reliability index derivation for reinforced concrete structures governed by serviceability limit state", Structural Concrete, (Early View) 2018.

https://doi.org/10.1002/suco.201800202

[90] Zitny, J., Ryjacek, P., Markova, J., Sykora, M. "Hidden Safety in Equilibrium Verification of a Steel Bridge Based on Wind Tunnel Testing", In: Life Cycle Analysis and Assessment in Civil Engineering: Towards an Integrated Vision: Proceedings of the Sixth International Symposium on Life-Cycle Civil Engineering (IALCCE 2018), Ghent, belgium, 2019, pp. 307-313.

[91] Thiis, T. K., O’Rourke, M. "Model for Snow Loading on Gable Roofs", Journal of Structural Engineering, 141(12), 2015. https://doi.org/10.1061/(ASCE)ST.1943-541X.0001286

\section{Annex A}

\section{A.1 Resistance variables}

\section{A.1.1 Material properties}

The variability of strength and deformation properties of steel results from its chemical composition, production technologies and quality control methods; testing procedure and sample size then affect statistical estimates of parameters describing randomness in material properties. To provide sufficiently general recommendations on appropriate probabilistic models, the database of experimental data should cover different steel grades, various types and thicknesses of rolled and welded steel products, etc. Such studies require involvement and intensive cooperation of a wide range of scientific and production organizations.

Such investigations are complicated in Belarus by the fact that rolled steel products are mainly delivered by foreign manufacturers. It thus seems reasonable to assess the statistical parameters of steel properties on the basis of recent international studies, taking into account 
the variability of rolled steel properties produced under different conditions. Based on an earlier study [19], Martynov and Nadolski [18] summarized the results of the investigation of yield strength variability performed in various countries. They recommended using a bias the ratio of actual yield strength to its characteristic value $\left(\mu_{f y} / f_{\mathrm{yk}}\right)$ - equal to $1.10-1.20$ and the coefficient of variation $V_{f y}=0.05-0.08$. It was suggested that partial factors be estimated while considering the values within these ranges as being equally likely.

Other studies focused on the calibration of partial factors considered:

- $\mu_{f \mathrm{y}} / f_{y \mathrm{k}}=1.19$ and $V_{f \mathrm{y}}=0.08[20] ; \mu_{f y} / f_{\mathrm{yk}}=1.27$ and $V_{f y}=0.057$ [21] without taking into account the variability of geometrical characteristics.

- $\mu_{R} / R_{\mathrm{k}}=1.25$ and $V_{R}=0.1[22] ; \mu_{R}=R_{\mathrm{k}} \mathrm{e}^{2} \mathrm{VR}$ and $V_{R}=0.08$ [23]; $\mu_{R} / \mathrm{k}=1.18$ and $V_{R}=0.08$ [24]; $\mu_{R}=R_{\mathrm{k}}+2 \sigma_{R}$ and $V_{R}=0.08$ [27] for resistance including the variability of geometrical characteristics.

where $\mu=$ mean value; $\sigma=$ standard deviation; $V=$ coefficient of variation $(\mathrm{CoV}) ; X_{\mathrm{k}}=$ characteristic value (the value taken from a standard that can be a specified fractile e.g. for material strength and ground snow loads, or a nominal value for dimensions or shape factors); $R=$ resistance; and $f_{\mathrm{y}}=$ yield strength of steel.

Normal or two-parameter lognormal distributions seem to be an appropriate probabilistic model for yield strength $[20,21,22,23,24,27]$. Normal distribution is supported by the fact that steel properties result from the sum of independent random values, none of which is dominant. The central limit theorem then suggests a normal distribution for a resulting variable. However, this is valid for the initial population; deviations from a normal distribution are frequently observed due to quality control and distributions become truncated or bimodal [28]. JCSS Probabilistic Model Code [17] recommends a two-parameter lognormal distribution.

\section{A.1.2 Geometrical characteristics}

The tolerances allowed in standards for rolled steel products, manufacturing and assembly of steel structures directly affect probabilistic models of geometrical dimensions. Some bias in geometrical characteristics is observed for common cross sections; for instance, it ranges from 0.99 to 1.03 for I-shaped rolled profiles. The coefficient of variation is small-0.01-0.03 [18]. More specifically, the following statistical characteristics have been reported in various studies:
- $\mu / X_{\text {nom }}=1.0$ and $V=0.04$ for sectional area, section modulus and moment of inertia of rolled profiles [10].

- $\mu / X_{\text {nom }}=1.025$ and $V=0.032$ for cross section area of IPE 140 [21].

- $\mu / X_{\text {nom }}=1.0$ and $V=0.03$ for the moment of inertia [26].

\section{A.1.3 Model uncertainty}

This type of uncertainty is related to imprecision and simplifications of theoretical models, which may include assumed stress distributions, boundary conditions, description of input data or simplifications made by analysts. Model uncertainty characteristics are commonly inferred from comparisons between model and test results $[17,70,71]$.

The general recommendations for resistances of steel members are provided by JCSS [17]: flexural and shear resistance $\mu=1$ and $V=0.05$; welded connections $\mu=1.15$ and $V=0.15$; and bolted connections $\mu=1.25$ and $V=0.15$. Detailed investigation of model uncertainty characteristics for steel members was published in [29].

The experience of the authors suggests that uncertainties in resistance models have so far been insufficiently analyzed. These uncertainties are often neglected in probabilistic reliability and calibration studies, though in some cases they dominate structural reliability. Consequently, these types of uncertainties may be inadequately reflected in the recommended values of partial factors. The generalization of statistical characteristics of model uncertainties is difficult due to continual improvements in resistance models.

Often, uncertainties associated with material properties, geometrical characteristics and model simplifications are described by a single random variable. For example, $\mu_{R} / R_{\mathrm{k}}=1.18$ and $V_{R}=0.15$ were recommended for resistances of steel structures including model uncertainty [25].

\section{A.2 Load effects}

\section{A.2.1 Permanent loads}

Permanent loads include the self-weight of load-bearing structural members, fixed equipment, prestressing and indirect actions caused by the rheological properties of materials and uneven settlements. The variability of selfweight is affected by uncertainties in structural dimensions, densities and the additional weight of connections. These effects are closely tied to the level of production and execution quality control. Dimensions and material densities are commonly described by normal distribution, 
rarely by truncated normal or lognormal distributions $[1,7,30]$. The statistical parameters of permanent actions are well-established for traditional construction materials.

Calibrations of the partial factors provided in Eurocodes are based on the following statistical characteristics of permanent loads $G$ : $\mu=1.05 G_{\mathrm{k}}$ and $V=0.07$ [10]; $\mu=1.05 G_{\mathrm{k}}$ and $V=0.1[12,25] ; \mu=G_{\mathrm{k}}$ and $V=0.1[23,31]$. The distinction between self-weight ( $\mathrm{CoV}$ for steel members 0.02 and 0.06 for concrete and glued timber members) and other permanent loads (coefficient of variation 0.1) was made in the SAKO technical report [32].

\section{A.2.2 Imposed loads}

Imposed loads are deemed to have similar characteristics in all European countries and thus generally accepted probabilistic models can be used. Most works [12, 13, 30,33] rely on the recommendations of JCSS [17]; the model recently recommended in the fib bulletin [59] is adopted herein (Table 3). These models are consistent with the results of the investigations undertaken in the 1980s [34, 35, 36, 37]. However, substantially different models were adopted when developing design provisions according to US standards [55].

In accordance with the JCSS Probabilistic Model Code [17], it is assumed that:

- Load changes during a reference period and associated uncertainties can be described by time-variant and time-invariant components.

- The time-invariant component is related to the simplifications in representing spatial variability of the load.

- The time-variant component consists of intermittent loadings (gathering of people, crowded rooms during special events, stacking of furniture during remodelling etc.) and sustained loadings (weight of furniture or heavy equipment) [17]; the latter often dominates the reliability of structural members and systems.

- Changes of the time-variant component are related to changes in use and of users of the building that occur each 5-10 years (the period of 5 years is conservatively considered hereafter).

- Short-term fluctuations of the load are included in the uncertainties of the time-variant component.

Uniformly distributed imposed load is often based on action averaged over a loaded area [17]. Analysis of uncertainties in such a load model [37] extended these recommendations and suggested statistical parameters of the unfirmly distributed load, loads acting on structural members and support reactions. When using a uniformly distributed load, bias in the bending moments was found to be 0.94 and associated $V=0.11$; for shear forces 1.1 and 0.06, respectively [37]. Considering the JCSS recommendations [17], uncertainty in imposed load - time-invariant component of the load model - is hereafter described by a two-parameter lognormal distribution (hereafter 'lognormal' for brevity) with unity mean and $V=0.1$.

\section{A.2.3 Snow load}

Snow load models are commonly based on annual maxima of ground snow loads. EN 1991-1-3 [39] indicates that annual snow maxima can be described by a Gumbel distribution if this is supported by available data. ISO 4355 [40] suggests Gumbel and lognormal distributions; the latter is deemed appropriate for regions with extreme loads resulting from one or more snowfalls. Snow load data recorded in Belarus justify the use of all the extreme value distributions - Gumbel, Weibull and Fréchet - that were applied in estimating the characteristic values - 98\% fractiles of annual maxima. For general reliability and calibration studies, the use of the Gumbel distribution is deemed preferable so as to be consistent with the present practice and assumptions in Eurocodes [1]. This is why a Gumbel distribution is considered hereafter.

The snow load models given in Eurocodes is based on a Gumbel distribution; 50-year maxima having the following parameters: $\mu=S_{\mathrm{k}}$ and $V=0.22$ [23]; $\mu=1.11 S_{\mathrm{k}}$ and $V=$ 0.27 [20]; and $\mu=1.11 S_{\mathrm{k}}$ and $V=0.33$ [41]. In all the works, the Gumbel distribution is adopted. Statistical parameters of the ground snow load maxima obtained for Belarus are summarized in $[30,38]$ and correspond well with those assumed for the calibration of Eurocodes.

Predicting events with a return period of hundreds or thousands of years ( $\sim$ design values in Eurocodes) from records spanning typically $40-60$ years is inevitably associated with significant uncertainties in selecting distribution type and parameter estimation [42, 43]. However, these 'statistical' uncertainties are typically disregarded in calibration studies. Though theoretical procedures allowing incorporation of statistical uncertainties are available, broader consensus on their implementation is presently missing. This is why these uncertainties are not included in the following analysis.

Snow load on the roof is obtained from the ground snow load by using shape, thermal and exposure factors [39]. Insufficient attention seems to be paid to uncertainties related to these coefficients. Note that the study by Thiis 
and O'Rourke [91], taken recently as a background for the revisions of the shape and exposure factors in ASCE 7 [66] and EN 1991-1-3 [39], reveals a bias in the Eurocode factors (mean to nominal value $\approx 0.8$ ) and considerable $\mathrm{CoV}$ $(\approx 20 \%)$. When considering these estimates, the partial factor for snow load slightly decreases.

In most works, uncertainty quantification follows the JCSS recommendations [17] - unbiased mean and $V=$ 0.15 ; this model is likewise adopted in this study.

\section{A.2.4 Wind action}

The probabilistic model of wind action should capture the randomness of the basic wind speed, basic wind pressure and coefficients that will make it possible to determine pressures and forces on a specific, dynamically loaded structure, including shape, gust, roughness and other factors. As is similar to the case of snow loads, a Gumbel distribution is a widely used model for annual maxima of wind speeds. Statistical uncertainty is commonly neglected and probabilistic description of time-invariant coefficients requires further research.

Uncertainty in the determining of wind pressure effects on a structure with a given shape, and located in terrain with some roughness, is described by JCSS [17]. Typically, a conservative bias in nominal values (0.8) and large $\mathrm{CoV}$ (up to 0.3) are assumed. Considering uncertainties in the time-invariant coefficients, 50 -year maxima of wind pressure were described by the following parameters: $\mu=0.7 W_{\mathrm{k}}$ and $V=0.35[12,44,45] ; \mu=0.9 W_{\mathrm{k}}$ and $V=0.34$ [25]; $\mu=$ $0.7 W_{\mathrm{k}}$ and $V=0.33$ [20]. Disregarding model uncertainties, the statistical parameters of extreme wind pressures for Belarus are provided in [30, 46]. Markowski [30] presented the statistical parameters for wind effect for the city of Brest in Belarus (wherein the coefficient variation of wind pressure is 0.27 ). Chernoivan [46] analyzed the data from 46 Belarusian meteorological stations for the period of 1966 - 2008. CoV of annual maxima of wind pressure ranged from 0.29 to 0.74 . However, these estimates were obtained from an inhomogeneous sample as different measurement techniques, methods of recording and different types of terrain affected the measurements for a particular location. The elimination of these effects would likely lead to reduced values of coefficient variation, $V_{X} \approx 0.3-0.5$.

It is important to note that the investigation by Botha et al. [64] revealed a number of factors which lead to concerns about representativeness of existing wind load probability models; the factors included:

- The discrepancies between probability models for different regions as demonstrated by the examples of South Africa and Central Europe

- The overall lack of consensus on wind load uncertainties, illustrated by the wide range of values obtained using the different models

- The lack of background data and information used to develop these models.

\section{A.2.5 Model uncertainty}

Uncertainties in the load effect model take into account inaccuracies in determining the load effect, such as internal forces and stresses resulting from model simplifications in geometry, supporting and boundary conditions, redistribution of forces amongst structural members, uncertainties in specifying model parameters that are unknown, etc. These uncertainties are described by a random variable $K_{E}$, the statistical parameters of which are adopted from [17]. Typically, the distinction between moments, axial and shear forces in frames and plates or stresses in plane and spatial structures is made. An unbiased mean is normally assumed; averaged $\mathrm{CoV}$ is 0.1 . 